\title{
Untargeted Metabolomics for Autism Spectrum Disorders: Current Status and Future Directions
}

\author{
Kevin E. Glinton * and Sarah H. Elsea* \\ Department of Molecular and Human Genetics, Baylor College of Medicine, Houston, TX, United States
}

Autism spectrum disorders (ASDs) are a group of neurodevelopment disorders characterized by childhood onset deficits in social communication and interaction. Although the exact etiology of most cases of ASDs is unknown, a portion has been proposed to be associated with various metabolic abnormalities including mitochondrial dysfunction, disorders of cholesterol metabolism, and folate abnormalities. Targeted biochemical testing like plasma amino acid and acylcarnitine profiles have demonstrated limited utility in helping to diagnose and manage such patients. Untargeted metabolomics has emerged, however, as a promising tool in screening for underlying biochemical abnormalities and managing treatment and as a means of investigating possible novel biomarkers for the disorder. Here, we review the principles and methodology behind untargeted metabolomics, recent pilot studies utilizing this technology, and areas in which it may be integrated into the care of children with this disorder in the future.

Keywords: autism, untargeted metabolomics, inborn errors of metabolism, metabolome, mass spectrometry, nuclear magnetic resonance spectroscopy

Sudeepa Br University of Arkansas for Medical Sciences, United States

*Correspondence: Kevin E. Glinton kevin.glinton@bcm.edu Sarah H. Elsea sarah.elsea@bcm.edu

Specialty section:

This article was submitted to Child and Adolescent Psychiatry, a section of the journal Frontiers in Psychiatry

Received: 28 January 2019

Accepted: 12 August 2019 Published: 10 September 2019

Citation:

Glinton KE and Elsea SH (2019) Untargeted Metabolomics for Autism Spectrum Disorders: Current Status and Future Directions.

Front. Psychiatry 10:647. doi: 10.3389/fpsyt.2019.00647

\section{INTRODUCTION}

The term "autism spectrum disorder" (ASD) describes a clinical spectrum of neurodevelopment conditions characterized by deficits in social communication and social interaction with restricted, repetitive patterns of behavior, interests, or activities (1). Although these core features have been recognized for over seven decades (2), only recently have we begun to recognize the largely heterogeneous nature of this disorder, with patients exhibiting varying degrees of impairments, medical complications, and intellectual disability (ID). In the United States, ASDs are estimated to have a prevalence of around 16.8 per 1,000 children older than 8 years ( 1 in 59), although in some subpopulations, this figure can be as high as 29.3 per 1,000 children (3). Having a child with ASD was found to be associated with an extra $\$ 17,081$ per year of additional costs to a family, including healthcare-associated costs, adaptive education, therapies, and family-coordinated services $(4,5)$. Not as easily measured, however, are the associated emotional and social stresses caregivers and family members encounter, often leading to depression, physical complaints, and declines in overall quality of life (6-8).

Because of the heterogeneity associated with ASD, tremendous efforts have been made to identify underlying mechanisms or markers for this complex set of disorders with limited success (Figure 1). Genetic variation, for instance, is thought to account for about $50 \%$ of the risk for ASD (9). While a portion of cases is thought to be due to common polymorphisms $(10,11)$, specific molecular diagnoses, like copy number variants or monogenic disorders, are, however, found in an estimated $30 \%$ to $40 \%$ of children with ASD, prompting the American College of Medical 


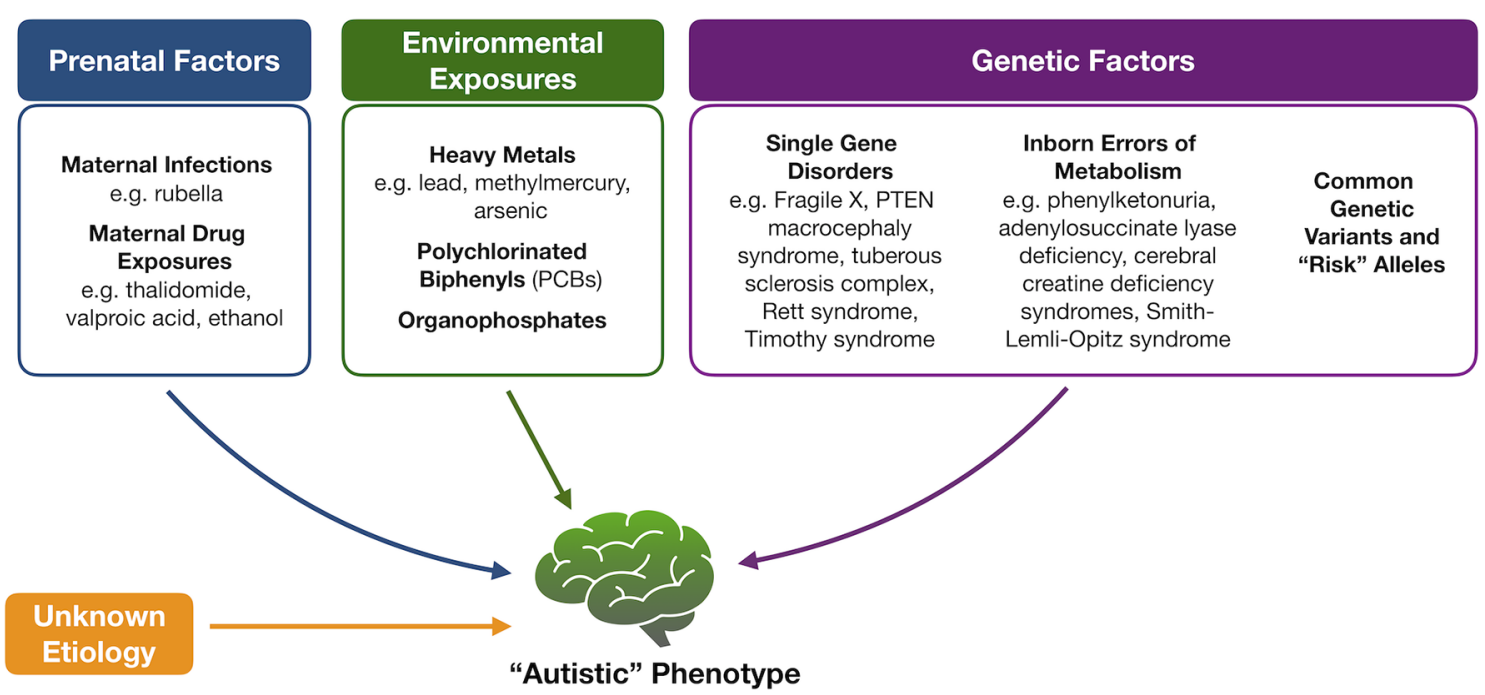

FIGURE 1 | Proposed etiologies for autism spectrum disorders. Multiple factors have been proposed to contribute to the development of autism spectrum disorder, including fetal exposures, childhood exposures, and underlying genetic causes that range from "risk" alleles to known Mendelian disorders and inborn errors of metabolism. In the majority of cases, however, an underlying etiology is not identified.

Genetics and Genomics to recommend at least chromosomal microarray and fragile $\mathrm{X}$ testing as a first diagnostic step (12). A small portion of ASD cases also occurs in patients with known inborn errors of metabolism (IEMs) $(13,14)$. The discovery of this association and the potential opportunity for therapeutic intervention have prompted the renewed search for characteristic neurometabolic biomarkers to aid in early screening and diagnosis of patients.

At present, routine metabolic testing has been recommended for patients with autism only on the basis of concerning physical examination features or historical details like seizures, developmental regression, or acidosis, provided the child has passed the relevant state-mandated newborn screening (12, 15). This is in contrast to recommendations from the American Academy of Pediatrics (16) in favor of an initial metabolic workup in patients with ID or global developmental delay (GDD), as these conditions are thought to be more likely of a metabolic nature. This dichotomous approach has raised some concerns including difficulties differentiating (17) the early signs of an isolated ASD from ID/GDD and the paucity of medical providers comfortable with recognizing the signs of an underlying IEM. The identification and use of a specific biomarker would therefore help differentiate these patients and also assist in streamlining the diagnostic process. One of the newest and most promising techniques available for identifying such biomarkers is untargeted metabolomics. Clinical uses of this technology have grown steadily over the past decade; however, its application to the study of autism remains limited for a variety of reasons. Given our current understanding of the various underlying causes, ASD appears to be an ideal disease state in which to apply this technology. Here, we describe the current neurometabolic framework of ASDs, outline the process and scope of untargeted metabolomics, survey the recent applications of untargeted metabolomics in individuals with ASD, and suggest ways in which this technology may expand in the future.

\section{METABOLOMIC PROFILING-A PRIMER}

The study of metabolomics refers to the systematic identification and quantitation of all metabolites in a given organism or biological sample (18). This collection of molecules, known as the metabolome, is thought to directly reflect the biochemical activity of the study system at a specific point in time. Metabolomic profiling is not a new concept, however. Archibald Garrod, for instance, first sought to describe the biochemical features of alkaptonuria in urine over a century ago (19). Decades later, Dalgliesh et al. (20), Gates and Sweeley (21), Horning and Horning (22) and Devaux et al. (23) were able to describe the characteristic profiles of various urinary and blood metabolites in the early 1960s-1970s using gas chromatography (GC) methods. In the last decade, however, technologic advancements in chromatographic and analytic techniques have allowed for a tremendous growth in the field of metabolomics, making it possible to identify hundreds, and sometimes thousands, of unique human analytes, leading to unprecedented insight into countless biochemical pathways (Figure 2).

Technically, metabolomic data are usually generated by use of nuclear magnetic resonance (NMR) spectroscopy and/ or mass spectrometry (MS) (24). Nuclear magnetic resonance spectroscopy uses radiofrequency (RF) waves to generate an electromagnetic field around a biological sample. Variations in this electromagnetic field lead to differential energy absorption and re-emission resulting in a spectrum of emitted $\mathrm{RF}$ waves corresponding to each metabolite (25). Although less commonly used for human samples, NMR has the advantage of minimal sample preparation and being able to not only 


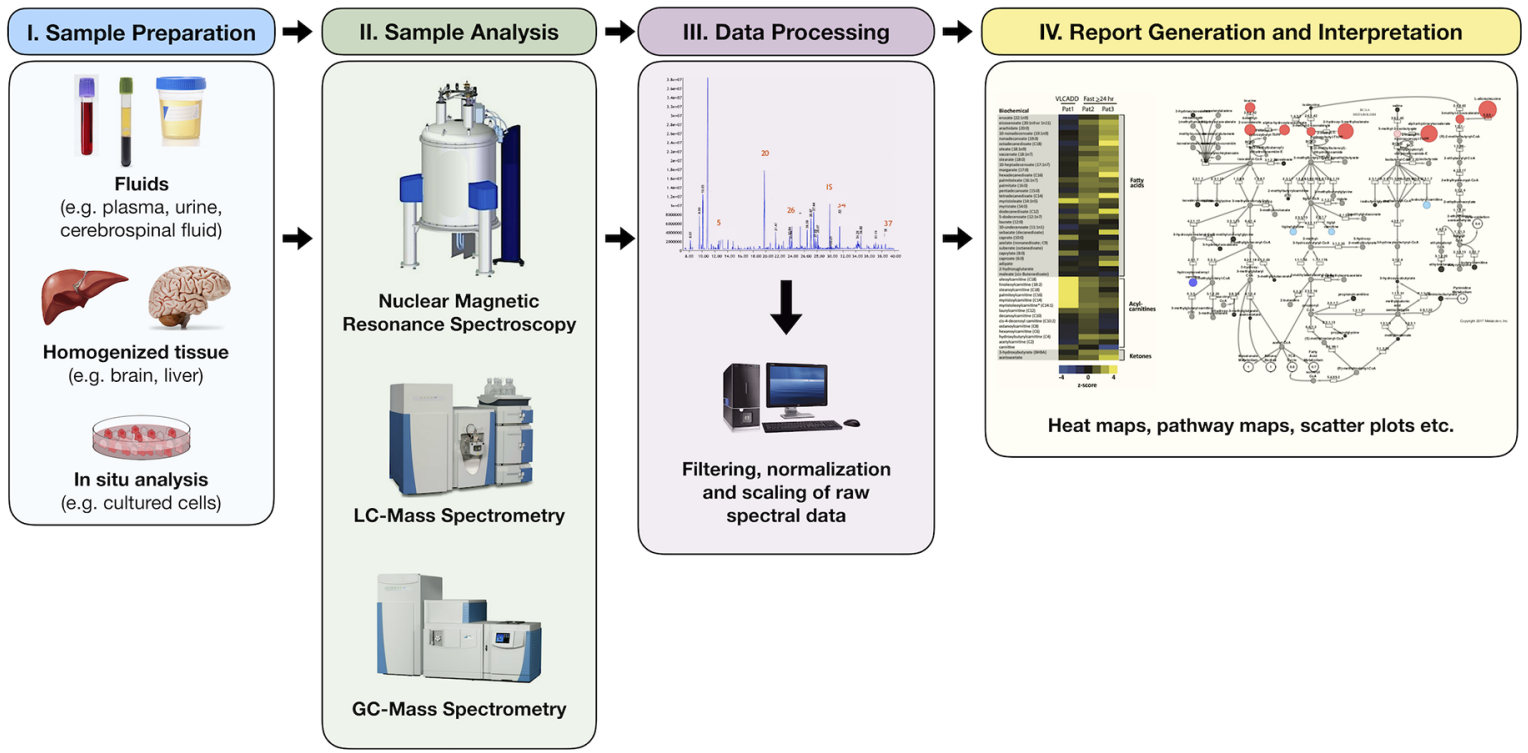

FIGURE 2 | Simplified process of metabolomic profiling. Samples are collected and undergo an initial processing step that may include homogenization and/ or centrifugation. This is followed by analysis via nuclear magnetic resonance or mass spectrometry techniques from which raw spectral data are collected. Raw data are then filtered, normalized, and scaled to ensure that analyte peaks may be accurately interpreted. Chemical compound libraries are utilized for accurate compound identification. The resultant data may then be plotted or reported in a variety of ways including heat maps, pathway enrichment maps, and scatter plots.

measure metabolite concentration but also identify the chemical structure. Mass spectrometry, on the other hand, makes use of the isolation of gas-phase ions based on their mass-to-charge ratio $(\mathrm{m} / \mathrm{z})(26)$. A sample is first separated by use of either a liquid chromatography (LC) or GC column and then ionized (27, 28). Individual peaks are generated for each metabolite with peak intensities corresponding to its relative concentration within the sample. Mass spectrometry-based methods have the advantage of greater sensitivity when compared to NMR, allowing for a larger number of measurable metabolites (29). Mass spectrometry protocols and analytical techniques, however, may vary greatly from one laboratory to another, making standardization and reproducibility of results more difficult when compared to NMR.

Metabolomic studies may be conducted as either targeted assays, where only a specific subset of metabolites is measured, or untargeted, where as many metabolites as possible are measured without filtering or bias. Both methods have their advantages and disadvantages, with the choice of test usually based upon experimental design and the specific hypothesis being tested (30). Targeted metabolomics, for instance, may be more desirable for the study of a single biochemical pathway where analysis can be focused on only a small group of molecules of interest. This approach has the advantage of limiting the analytical and statistical burden of an experiment, although one risks missing perturbations of secondarily interconnected pathways. Untargeted metabolomics, on the other hand, has the advantage of revealing unique and previously unrecognized changes in metabolites and enzymatic pathways, although the quantity and complexity of experimental data can be challenging $(31,32)$.
Regardless of the technique, however, it is now theoretically possible to perform metabolomic profiling on almost any tissue, opening up a wealth of potential biochemical information (33). Naturally, metabolomic profiling has found extensive use in the diagnosis and treatment of IEMs, although the test has also helped establish new or previously unrecognized aspects of several other genetic conditions, as well (34-36). In addition, metabolomic profiling has also been used to study to a broader variety of human diseases including obesity and insulin resistance $(37,38)$, myocardial ischemia and other models of cardiovascular disease $(39,40)$, hepatocellular disease $(41,42)$, and malignancies $(43,44)$.

\section{AUTISM AND INBORN ERRORS OF METABOLISM}

Inborn errors of metabolism are themselves rare diagnoses with combined incidences between 1 in 800 and 1 in 2,500 individuals $(45-48)$. It is estimated that only up to $5 \%(49,50)$ of children with ASD will be found to have an IEM, although these disorders are important to consider when confronting a first-time patient. Over the years, many different case reports have attempted to link various IEMs with the development of autism; however, it is important to keep in mind the refinements that have been made over time to the definition of ASD in contrast to other behavioral disorders, developmental delay, and ID. As such, many of these earlier associations have since been shown to be tenuous (51) or at least only single cases, and we therefore restrict our discussion here to disorders in which multiple pieces of evidence support 
the link between the biochemical findings and the observed clinical phenotype of ASD.

Prior to the advent of universal newborn screening in the United States, many children with these disorders may have initially come to medical attention for "autistic" features and developmental delay. With screening protocols, this is no longer the case, although several IEMs still predispose patients to ASD, despite early identification and adequate treatment $(52,53)$. We previously demonstrated that untargeted metabolomics may be used to identify many of the diagnostic and even secondary changes in downstream analytes (34). This approach also allows for the complete elucidation of abnormal biochemical pathways and in some cases can offer clues to fundamental abnormalities that may lead to an autistic phenotype in all children.

One example of a known IEM associated with ASD is phenylketonuria (PKU; OMIM 261600), a disorder due to defects in the phenylalanine hydroxylase enzyme system. Children with "classical" PKU have little to no enzyme activity and as a result may have serum phenylalanine concentrations many orders of magnitude greater than unaffected individuals. Metabolomic studies on patients with PKU have demonstrated elevated serum levels of phenylalanine derivatives, including phenylpyruvate, phenylacetate, phenyllactate, mandelic acid, 4-hydroxyphenylacetic acid, and several others $(54,55)$. It remains unclear which of the abnormal analytes, however, truly lead to the toxic effects observed in patients. Based on urine studies, compounds like phenylpyruvate and phenylacetate have been proposed as more efficient markers for disease than direct measurement of phenylalanine, given ease of obtaining urine samples and a low false-negative diagnostic rate (54). Along with possible direct toxicity, elevated phenylalanine levels are thought to decrease the cerebrospinal fluid (CSF) concentrations of tyrosine and its downstream products like serotonin and dopamine. This hyperphenylalaninemia is also thought to inhibit the transport of large neutral amino acids across the brain, decrease protein synthesis within the brain, and increase myelin turnover with eventual hypomyelination, all processes that may or may not contribute to the development of autism $(56,57)$.

Without early treatment, PKU leads to severe intellectual impairment along with physical features like fair skin, spastic gait, and microcephaly (58). While the incidence of PKU has remained steady at around 1 in 11,400 live births in the United States (59), newborn screening and the early institution of various treatment modalities have greatly reduced the number of severely affected individuals. Prior to newborn screening, up to $21 \%$ (60) of cases of "autism" were later found to have biochemical evidence of untreated PKU, and in a recent study, about $5.7 \%$ of untreated patients were diagnosed with ASD (61). Overall, however, in countries where universal newborn screening has rendered "symptomatic" PKU almost nonexistent, it is estimated that only $0.7 \%$ (62) of patients with a diagnosis of PKU will meet the criteria for ASD. While this figure is significantly lower than previous estimates, it is still higher than age-matched controls, highlighting a possible link between the biochemical abnormalities in PKU and a susceptibility to ASD.

Autistic features also appear to be a commonly observed in Smith-Lemli-Opitz syndrome (SLOS; OMIM 270400), an autosomal recessive disorder of cholesterol biosynthesis occurring in approximately 1:20,000 to 1:40,000 live births (63-66). Affected individuals are deficient in the enzyme 7-dehydrocholesterol reductase (DHCR7; OMIM 602858), the final enzyme in the synthesis of cholesterol, and as a result exhibit abnormally high serum concentrations of 7-dehydrocholesterol and its isomer 8-dehydrocholesterol (67). Total cholesterol levels appear to correlate inversely to the severity of symptoms, although in most patients there is still usually some detectable cholesterol in serum. Cholesterol levels are, however, severely decreased within the brain parenchyma where cholesterol is known to play important roles in embryonic and fetal brain development, myelination, and ongoing synthesis of neurosteroids (68-71). Studies suggest decreased central nervous system (CNS) cholesterol as the cause of the neurodevelopment manifestations of SLOS, as well as the high incidence of ASDs in this population (72). Approximately $50 \%$ of children with SLOS also fulfill clinical criteria for a diagnosis of an ASD, suggesting a common pathomechanism between the two disorders (52). Interestingly, this hypothesis is also supported by the finding of significant hypocholesterolemia in up to $20 \%$ of children with isolated ASD (73).

The biochemical defect known as adenylosuccinate lyase (ADSL) deficiency (OMIM 103050) has also been described as a disease particularly associated with the development of ASD. Although rare, with an estimated prevalence of only 1 in $1,240,710$ individuals (74), approximately $30 \%$ (75) of patients with ADSL deficiency exhibit autistic features along with other findings like developmental delay, encephalopathy, seizures, and growth retardation. The disorder is caused by an autosomal recessive defect in ADSL (OMIM 608222), which encodes the enzyme ADSL involved in the de novo synthesis of purines. The disease is characterized biochemically by the presence of the compounds succinylamino-imidazole carboxamide riboside (SAICA riboside) and succinyladenosine (S-Ado) in the CSF, plasma, and urine of affected patients $(76,77)$. Although both compounds are easily assayed through targeted testing, ADSL deficiency is easily identified on untargeted metabolomics by strikingly high levels of S-Ado in both plasma and CSF (78). Accumulated SAICA riboside is thought to be the primary neurotoxicant involved in this disorder, based on animal models (79). Deficiencies in ADSL are also believed to lead to decreased purine levels within the CNS, although the exact physiologic consequences of this are somewhat unclear. There is also some evidence that ADSL deficiency may lead to altered cerebral energy metabolism through the interactions between fumarate and AMP with purines (80).

Finally, much insight into the underlying mechanism of ASD may also be gained from the group of disorders known as cerebral creatine deficiency syndromes (CCDSs). This group of abnormalities comprised the three enzymatic defects in the synthesis of creatine:arginine:glycine amidinotransferase (AGAT) deficiency (OMIM 612718), guanidinoacetate methyltransferase (GAMT) deficiency (OMIM 612736), and SLC6A8 deficiency (OMIM 300352). The creatine:phosphocreatine system plays an essential role in ongoing energy metabolism by serving as a reservoir for phosphate moieties in their transfer back and forth from ATP to ADP (81). In humans, creatine may be either taken 
in through the diet or synthesized de novo from precursors via the activity of the enzymes AGAT and GAMT in tissues like the kidney pancreas and liver. The molecule may then be transported into its target tissues via the action of its sodium chloridedependent channel (SLC6A8). Genetic abnormalities in any of these three components lead to a severe deficiency of creatine within the brain parenchyma, with the diagnostic hallmark of the disease being an almost absent creatine peak on ${ }^{1} \mathrm{H}$ NMR spectroscopy. While it remains unsettled as to what proportion of creatine within the fetal brain is imported versus synthesis natively, it is clear that this small molecule plays an integral part in ongoing neurodevelopment (82).

Clinically, patients with CCDS exhibit a combination of developmental delay particularly in expressive language, ID, and autistic behaviors (83). The incidence of autistic features appears to vary for each of the three disorders. Approximately $78 \%$ to $95 \%$ of patients with GAMT deficiency have been reported to have autistic features, while only $41 \%$ of patients with SLC6A8 deficiency were felt to exhibit the same behaviors (84-86). As the rarest of the CCDS, accurate estimations of the occurrence of ASD in AGAT deficiency are difficult, although 4 of 16 total patients (25\%) were reported to have features of autism in one recent study (87). The phenotype is thought to arise due to deficits in cerebral energy production during and after fetal development, the accumulation of the potentially neurotoxic guanidinoacetate and other guanidino compounds, and possible abnormalities in ongoing neural signaling associated with abnormalities in the creatine-phosphocreatine system (88). Interestingly, treatment of patients with creatine supplementation and arginine restriction in the case of GAMT patients does seem to improve certain aspects of their phenotype, although not all concerns are eliminated. GAMT patients, for instance, do experience improved seizure control and a decrease in movement disorder symptoms, although severe ID remains. Patients with AGAT deficiencies do appear to fare better with some catch-up development and even prevention of symptoms entirely in a prenatally known case. Creatine supplementation does not, however, appear effective for patients with SLC6A8 deficiency, as increased plasma levels are not able to compensate entirely for abnormal transport across the blood-brain barrier.

Other IEMs have been associated with an increased incidence of ASD. These include so-called classical disorders like propionic academia (OMIM 606054) (53), various urea cycle disorders (89), and Sanfilippo syndrome (OMIM 252900, 252920) (90), as well as rarer disorders like succinic semialdehyde dehydrogenase deficiency (OMIM 271980) (91) and branched-chain ketoacid dehydrogenase kinase deficiency (OMIM 614901) (92).

\section{AUTISM AND NONSPECIFIC METABOLIC DISTURBANCES}

While known IEMs are informative as to the development of ASD in a subset of patients, there are also other nonspecific metabolic abnormalities that have been explored within this population. Given that the metabolome of different body compartments may consist of hundreds to thousands of compounds, subtle changes identified in a clinical condition can also lead to clues to its mechanism or even treatment. It is important to mention briefly the emerging work $(93,94)$ on interactions between gut microbiota and the development or even exacerbation of autistic symptoms. It is now well recognized that humans exist in constant symbiosis with thousands of species of microorganisms. Microorganisms have been postulated to help defend against the colonization of pathogenic species and aid in the synthesis of some vitamins and nutrients, as well as help educate the nascent immune system (95-97). Evidence has begun to emerge, however, on the role these microorganisms, particularly in the large intestine, may play in neurodevelopment and behavioral phenotypes with dysbiosis in particular, proposed as a possible mechanism for the development ASD (98-101). Both targeted and untargeted analyses have been used to identify microbiomeassociated metabolites in fecal samples $(102,103)$, as well as effects on plasma/serum $(104,105)$ lending further evidence to the importance of these organisms. Fecal concentrations of compounds like isopropanol, p-cresol (103), and various shortchain fatty acids (106) have been demonstrated to be altered in patients with ASD. Similarly, human plasma studies in patients with ASD have demonstrated abnormal branched-chain amino acid levels (105), while transfection of mice with microorganisms from these individuals has also led to behavioral changes in mice in multiple studies $(104,107)$. This particular area of research has grown exponentially in the last decade and will only continue to grow further in the future as assay techniques and methodologies improve.

Mitochondrial dysfunction has been explored as a possible cause or contributor to an autistic phenotype for several decades. Coleman and Blass (108) first identified the presence of lactic acidosis in a small set of patients in 1985, with Lombard (109) later proposing that ASD may be at least partially due to abnormal neuronal oxidative phosphorylation. Since that time, numerous studies have emerged attempting to further delineate the exact role of mitochondria in ASD, with several excellent reviews and meta-analyses on this single topic alone $(110,111)$. Mitochondrial dysfunction would appear to be the ideal candidate for a possible cause for ASD given the critical role mitochondria play in ATP production, calcium homeostasis, and synaptic plasticity within neurons $(112,113)$. Mitochondrial ATP production primarily involves the five respiratory complexes and two electron carriers that collectively make up the electron transport chain: NADH dehydrogenase, succinate dehydrogenase, coenzyme Q10 (CoQ10)-cytochrome $\mathrm{C}$ reductase, cytochrome $\mathrm{C}$ oxidase, ATP synthase, and the electron carriers CoQ10 and cytochrome C. In such a highly regulated and intricate process, it is easy to imagine that any number of molecular changes would have significant effects on overall energy production and neural function.

Mitochondrial dysfunction has been identified in a subset of individuals with ASD utilizing biochemical markers, clinical criteria, direct enzyme assay, and molecular methods. Oliveira and colleagues (114), for example, found that $20.3 \%$ of patients in their cohort had elevated plasma lactate levels. Eleven of these patients eventually underwent muscle biopsy, and five of the patients $(7.2 \%)$ exhibited clearly deficient respiratory chain enzyme activity, most commonly in complexes I, IV, and V. 
Aside from two patients with suggestive family histories, these patients were otherwise indistinguishable from the remainder of the cohort with no seizures, loss of motor skills, or abnormal physical examinations. This lack of physical findings or suggestive medical histories, however, has been challenged by a similar later study by Weissman et al. (115). That group identified 25 patients with autism and either molecular or enzymatic evidence of a primary mitochondrial disorder, and all of the patients had met clinical criteria for "probably or definite" mitochondrial disease by the Modified Walker Criteria or the Mitochondrial Disease Criteria. In this cohort, patients exhibited a number of systemic complications including seizures (20\%), exercise intolerance (68\%), gastrointestinal dysfunction (64\%), and gross motor delays $(32 \%)$. Twenty of the patients $(80 \%)$ had confirmed respiratory chain complex deficiencies on direct enzyme analysis, with 16 patients having complex I defects, in particular. Two patients had likely pathogenic mtDNA point mutations (A3397G, A4295G), while a further four patients had variants of uncertain clinical significance. Other cases of pathogenic mitochondrial variants have appeared sporadically throughout the literature. Graf et al. (116), for instance, described a family affected by the variant G8363A, which encodes the mitochondrial transfer RNA ${ }^{\text {Lys. The }}$ variant was found in a female child with a clinical diagnosis of Leigh syndrome and in her brother, who was otherwise healthy aside from a diagnosis of autism. In this case, the male patient was found to have a lower level of heteroplasmy than his more severely affected sister hinting at a likely causative role for this variant in the development of his autism. Pons et al. (117) also identified the MELAS-associated mtDNA variant, A3243G, in two out of five individuals with ASD. Of the other three patients in the study, one patient had evidence of mitochondrial depletion on muscle biopsy, while the other two had mothers known to carry the A3243G variant. The authors speculated that, given variations in heteroplasmy, these subjects may have had clinically undetectable levels in plasma, but higher levels in the brain. There are also reports of differing levels in mtDNA expression, possible mitochondrial depletion, and deletions/copy number variations in small cohorts $(118,119)$. Investigations into mitochondrial single-nucleotide polymorphisms as susceptibility loci have also taken place, although these have yielded conflicting results over time (120-123).

Mitochondrial dysfunction, when present, appears to be localized to specific regions in the brains of affected patients. A 2011 study on postmortem brain samples, for instance, demonstrated low electron transport chain (ETC) activity levels in the cerebellum, frontal and temporal cortices of younger subjects (aged 4-10 years) when compared to age-matched controls (124). In this case, complexes III and V activity levels were statistically decreased in the cerebellum, while complex I was decreased in the frontal cortex, and complexes II, III, and $\mathrm{V}$ were decreased in the temporal cortex. A 2013 study by the same group confirmed deficient complex I activity in the frontal cortex, although complex $\mathrm{V}$ was also significantly affected in these cases (106). Deficient ETC activity was also confirmed in temporal lobe samples by Tang and colleagues (125), although in this case the group found significantly decreased complexes I and IV activities when patients were compared to controls.
Oxidative phosphorylation is just one of many functions of mitochondria thought to be critical to neural development. There has also emerged significant work on the role of oxidative stress on the development of autism. Reactive oxygen species (ROS), generated either endogenously or through exposure to toxic environmental substances, may cause significant cellular damage if not disposed of efficiently through the body's antioxidant systems. These include enzymes like superoxide dismutase and catalase and nonenzymatic compounds like glutathione (GSH). Some posit that ASD may emerge when the balance between these two systems is somehow upset either through the cumulative buildup of ROS or through genetic predispositions in the form of molecular defects in the antioxidant system. Several studies have, for instance, confirmed the presence of increased oxidative stress in plasma in patients with ASD (126). A 2012 meta-analysis, in fact, demonstrated that on average patients with ASD had a $27 \%$ lower plasma concentration of GSH with corresponding 45\% higher plasma levels of reduced GSH (GSSG) when compared to health controls (127). There are also studies on the sometimes characteristic patterns of oxidative damage within the brain tissue of autistic patients. These experiments have relied on direct GSH and GSSG measurements, as well as the detection of various "marker" compounds for oxidative stress like 3-nitrotyrosine (3-NT), carboxyethyl pyrrole, and 8-hydroxydeoxyguanosine (8-OH-dG) (128-130). Glutathione levels were found to be $34.2 \%$, and $44.6 \%$ decreased in the cerebellum and temporal cortices, respectively, when compared to controls $(131,132)$. Interestingly, relatively little change was seen in the prefrontal cortex of patients, an observation that was also confirmed in a later direct MRS study (133). Levels of 3-NT and 8-OH-dG were similarly elevated within the cerebellum $(129,130,133)$.

Defects in carnitine biosynthesis have been postulated to predispose individuals to nonsyndromic autism (134). Carnitine plays a variety of physiologic roles, but most important is its ability to help shuttle long-chain fatty acids into mitochondria for $\beta$-oxidation. In humans, approximately $75 \%$ of carnitine is obtained from the diet, with the remainder synthesized endogenously from the amino acids lysine and methionine (135). Carnitine deficiency has been associated with complications like cardiomyopathy and myopathy, and decreased carnitine levels have been previously described in a subset of children with ASD (136). In a 2012 study by Celestino-Soper et al. (137), carnitine biosynthesis defects were linked to an increased risk for ASD among males. Patients were found to carry a deletion in TMLHE (OMIM 300777), which encodes 6-N-trimethyllysine dioxygenase, the first enzyme in carnitine biosynthesis. The deletion is estimated to occur in approximately 1 in 350 males of European descent; however, it is also almost three times more common in families with more than one male diagnosed with ASD. Interestingly, the affected patients did not have evidence of ongoing systemic carnitine deficiencies, although plasma and urine studies were able to clearly demonstrate abnormal carnitine metabolites. It remains unclear whether or not TMLHE deficiency acts as a risk factor alone, or if there are other as yet unidentified toxic metabolites that build up as a result of this particular enzyme deficiency. There continues to be ongoing interest in this possible contributor for ASD, however, because of 
the potential for an easy and inexpensive treatment in the form of L-carnitine supplementation.

Finally, there has long been an association observed between ASD and immune dysfunction; however, the exact nature of this relationship remains complex (138-141). Although many of the earlier studies in this area were limited to "patient-reported" symptoms only, more recent studies have relied instead on more careful and systematic review of medical records instead. As a result, a greater evidence base suggests a relationship between the pathogenesis of ASD and prenatal and postnatal immune dysregulation. Atladottir et al. (142), for instance, described increased rates of rheumatoid arthritis and celiac disease in mothers of children with ASD and a higher rate of type 1 diabetes mellitus in both mothers and fathers of children with ASD. Immune dysfunction has also been directly demonstrated in individuals with ASD themselves. Careaga et al. (143) showed, for example, that the peripheral blood mononuclear cells of boys with ASD exhibited characteristic immune responses based on lipopolysaccharide or phytohemagglutinin stimulation. Abnormal neuroinflammatory changes have also been demonstrated, including prominent microglia activation and increased inflammatory cytokine and chemokine production (144-146). While most metabolomic studies are unable to assay compounds as large as cytokines, chemokine, or antibodies, immune responses may lead to measurable alterations in amino acids metabolites, glycolytic, gluconeogenic, oxidative stress, and purine intermediates (147). This complex interplay between immune dysregulation and the development of ASD continues to be an active area of ongoing research, and clearly, we are only now beginning to recognize the extent to which other physiologic processes are affected as well.

\section{TOWARDS BIOMARKERS FOR AUTISM- THE CLINICAL APPLICATION OF METABOLOMICS}

The variety of metabolic disturbances identified in patients appears to suggest that ASDs may represent a common endpoint for multiple different abnormal neuronal pathways. The question remains: To what extent can any one test or biomarker adequately assay all of the individual pathways involved in such pathways and how can that information be best used to guide individual risk or even treatment? The answer to this question may, in fact, lie in the use of untargeted metabolomics in patients with ASDs. The idea of broadly surveying the metabolic environment of patients is certainly not new, despite the changes in terminology over the years. Jaeken and Van den Berghe (76), for instance, first performed broad metabolic testing on three children with severe developmental delay and autistic features in 1984. The children all had extensive biochemical testing performed including serum ammonia, pyruvate, lactate, uric acid, arylsulfatase A, phytanic acid and amino acids, urine amino acids, organic acids, and mucopolysaccharides, along with CSF amino acids, sugars, and inorganic phosphate. The subjects were all eventually diagnosed with ADSL deficiency, thus demonstrating early on the kind of utility such expansive analyses can have in this population. While large-scale, untargeted metabolomic studies remain relatively uncommon, there have been small-scale attempts to prove the applicability of this strategy. We highlight in Table 1 the studies published thus far that overall paint a promising picture for the application of this technology. One caveat that must be considered, however, is that many of these studies did not take into account differences in patients' diets, medications, and supplement use, which may or may not have been contributors to the findings in several cases.

\section{Urine Untargeted Metabolomics}

Many of the original metabolomic studies were conducted on urine samples, understandably due to its readily availability, particularly in children with an underlying neuropsychiatric disorder. While some of these studies have yielded particularly compelling results, as a whole, clearly consistent and conclusive findings have not been shown. Yap et al. (148) described characteristic perturbations in the urine of 39 children with autism when compared to 28 of their phenotypically normal siblings. Proton NMR analysis was able to identify several dozen compounds and revealed that the urine of subjects contained lower levels of hippurate and phenylacetylglutamine (PAG) with higher levels of dimethylamine (DMA). Nicotinic acid metabolites like $\mathrm{N}$-methyl nicotinic acid, $\mathrm{N}$-methyl nicotinamide, and $\mathrm{N}$-methyl2-pyridone-5-carboxamide were also increased, as were the small molecules taurine and succinate. The group speculated that the observed metabolic abnormalities may have been due to gut microbiota in the case of hippurate and PAG and abnormal energy metabolism in the case of succinate. Given its role in the tryptophan-tryptophan-serotonin-melatonin pathway, the group also speculated that the abnormalities in nicotinic acid and its metabolites may be a contributor to the disordered sleep pattern observed in autistic patients.

These findings were somewhat limited by the overlap of many of the spectral peaks, which presumably led to a relatively small number of unique compounds that could be identified. To mitigate this, Mavel et al. (150) expanded on the use of NMR by performing two-dimensional studies on urine instead. The technique called heteronuclear single quantum coherence (2DNMR HSQC) uses both ${ }^{1} \mathrm{H}$ NMR and ${ }^{13} \mathrm{C}$ NMR to generate a twodimensional metabolite map with each nucleus corresponding to an axis. This decreases the likelihood of spectral overlap and results in the identification of a larger number of metabolites than standard one-dimensional NMR. Using this, the researchers were able to identify more than 150 metabolites in the urine of 30 children with autism and 28 healthy controls. There were once again increased levels of taurine and succinate observed; however, other molecules like glycine and $\beta$-alanine were also elevated when subjects were compared to controls. In contrast to the work by Yap et al (148), there were no statistical differences between the two groups in terms of glutamate, DMA, trimethylamine $\mathrm{N}$-oxide, or hippurate.

Gas chromatography-MS studies on urine samples have also been carried out by groups both in the US and Europe in rapid succession between 2012 and 2014. The first of these was 
TABLE 1 | Previous studies utilizing untargeted metabolomics in subjects with autism spectrum disorders.

\begin{tabular}{|c|c|c|c|c|c|c|}
\hline \multirow[t]{2}{*}{ Study Reference } & \multirow[t]{2}{*}{ Study Population } & \multirow{2}{*}{$\begin{array}{l}\text { Age } \\
\text { Range } \\
\text { (y) }\end{array}$} & \multirow[t]{2}{*}{ Tissue } & \multirow[t]{2}{*}{ Study Method } & \multicolumn{2}{|c|}{ Notable Metabolites } \\
\hline & & & & & Increased & Decreased \\
\hline Yap et al., (148) & $\begin{array}{l}39 \text { children with ASD } \\
28 \text { "nonautistic" siblings } \\
34 \text { age-matched controls }\end{array}$ & $3-9$ & Urine & ${ }^{1} \mathrm{H} N \mathrm{NMR}$ & $\begin{array}{l}\text { Dimethylamine, taurine, succinic acid, } \\
\mathrm{N} \text {-methylnicotinic acid, } \mathrm{N} \text {-methylnicotinamide, } \\
\mathrm{N} \text {-methyl-2-pyridone-5-carboxamide }\end{array}$ & Hippurate, phenylacetylglutamine \\
\hline Ming et al., (149) & $\begin{array}{l}48 \text { children with } A S D \\
53 \text { age-matched controls }\end{array}$ & $6-14$ & Urine & $\begin{array}{l}\text { UPLC-MS/MS and } \\
\text { GC-MS }\end{array}$ & $\begin{array}{l}\text { trans-Urocanate, glutaroylcarnitine, } \\
\text { 3-methylglutaroylcarnitine }\end{array}$ & $\begin{array}{l}\text { Glycine, serine, threonine, alanine, } \beta \text {-alanine, histidine, } \\
\text { taurine, carnosine, uric acid }\end{array}$ \\
\hline Mavel et al., (150) & $\begin{array}{l}30 \text { children with ASD } \\
28 \text { age-matched controls }\end{array}$ & $\begin{array}{l}6-14 \\
6-9\end{array}$ & Urine & ${ }^{1} \mathrm{H}-{ }^{13} \mathrm{C} \mathrm{NMR}$ & Glycine, $\beta$-alanine, taurine, succinic acid & Creatine, 3-methylhistidine \\
\hline Emond et al., (151) & $\begin{array}{l}26 \text { children with ASD } \\
24 \text { age-matched controls }\end{array}$ & $\begin{array}{l}6-14 \\
6-9\end{array}$ & Urine & GC-MS & Succinic acid, glycolic acid & $\begin{array}{l}\text { Hippurate, phosphate, palmitate, stearate, } \\
\text { 3-methyladipate }\end{array}$ \\
\hline Noto et al., (160) & $\begin{array}{l}21 \text { children with ASD } \\
21 \text { "nonautistic" siblings }\end{array}$ & $\begin{array}{l}4-16 \\
4-17\end{array}$ & Urine & GC-MS & $\begin{array}{l}\text { Glycolic acid, homovanillic acid, } \\
\text { 3,4-dihydroxybutyric acid, tryptophan }\end{array}$ & Fructose, 1,2,3-butanetriol, propylene glycol \\
\hline Dieme et al., (152) & $\begin{array}{l}30 \text { children with } A S D \\
32 \text { age-matched controls }\end{array}$ & $\begin{array}{l}5-12 \\
4-13\end{array}$ & Urine & $\begin{array}{l}{ }^{1} \mathrm{H} \mathrm{NMR},{ }^{1} \mathrm{H}-{ }^{13} \mathrm{C} \text { HSQC } \\
\text { NMR, and LC-HRMS }\end{array}$ & $\begin{array}{l}\mathrm{N} \text {-acetylarginine, indoxyl, indoxylsulfate, dihydroxy- } \\
1 \mathrm{H} \text {-indole glucuronide I }\end{array}$ & Methylguanidine, desaminotyrosine, dihydrouracil \\
\hline Bitar et al., (153) & $\begin{array}{l}40 \text { children with ASD } \\
40 \text { age-matched controls }\end{array}$ & $\begin{array}{l}3-15 \\
3-15\end{array}$ & Urine & $\begin{array}{l}{ }^{1} \mathrm{H} N M R,{ }^{1} \mathrm{H}-{ }^{13} \mathrm{C} \text { NMR, } \\
\text { and LC-HRMS }\end{array}$ & $\begin{array}{l}\text { Phosphoserine, glutamic acid, nicotinamide } \\
\text { ribotide, trigonelline, 5-amino-imidazole-4- } \\
\text { carboxamide, riboflavin, glycerol-3-phosphate, } \\
\text { chalice acid, }\end{array}$ & $\begin{array}{l}\text { Threonine, creatine, serine, } \mathrm{N} \text {-acetylphenylalanine, } \\
\text { tyrosine, hydroxybenzoic acid, hydroxyproline, } \\
\text { urocanic acid, cysteic acid, 2-hydroxybutyric } \\
\text { acid, citric acid, guanine, } \mathrm{N} \text {-amidino aspartic acid, } \\
\text { acetylcarnitine, methyl acetoacetic acid, }\end{array}$ \\
\hline $\begin{array}{l}\text { Kuwabara et al., } \\
(154)\end{array}$ & $\begin{array}{l}25 \text { individuals with ASD } \\
28 \text { age-matched controls }\end{array}$ & $\begin{array}{l}23-39 \\
24-36\end{array}$ & Plasma & CE-TOFMS & Arginine, taurine & 5-Oxoproline, lactic acid \\
\hline West et al., (155) & $\begin{array}{l}52 \text { children with ASD } \\
30 \text { age-matched controls }\end{array}$ & $6-9$ & Plasma & LC-MS and GC-MS & $\begin{array}{l}\text { Aspartate, serine, DHEA-S, glutaric acid, succinic } \\
\text { acid }\end{array}$ & $\begin{array}{l}\text { Citrate, creatinine, isoleucine, hydroxyphenyllactate, } \\
\text { glutamate }\end{array}$ \\
\hline Wang et., al., (156) & $\begin{array}{l}173 \text { children with ASD } \\
163 \text { age-matched controls }\end{array}$ & $3-6$ & Plasma & UPLC/Q-TOF-MS/MS & Decanoylcarnitine, pregnanetriol & $\begin{array}{l}\text { Sphingosine-1-phosphate, docosahexaenoic acid, } \\
\text { adrenic acid, uric acid }\end{array}$ \\
\hline $\begin{array}{l}\text { Rangel-Huerta } \\
\text { et al., (157) }\end{array}$ & $\begin{array}{l}20 \text { children with ASD } \\
30 \text { age-matched controls }\end{array}$ & $\begin{array}{l}2-6 \\
2-6\end{array}$ & Plasma & UPLC-MS/MS & $\begin{array}{l}\text { 3-Indoxyl sulfate, 6-hydroxyindole } \\
\text { sulfate, tryptophan, 5-bromotryptophan, } \\
\text { gamma-glutamylmethionine, methionine, } \\
\text { ursodeoxycholate, cortisone, sphingomyelins } \\
\text { d182, kynurenine, 1-methylnicotinamide, } \\
\text { choline phosphate, 4-methyl-2-oxopetane, } \\
\text { decanoylcarnitine }\end{array}$ & $\begin{array}{l}\text { Behenate, sebacate decanedione, arachidate, } \\
\text { glutamate, aspartate, orotate, 2-keto-3- } \\
\text { deoxyglutamate, galactitol, } \mathrm{N} \text {-acetyl-aspartyl } \\
\text { glutamate, fructose }\end{array}$ \\
\hline $\begin{array}{l}\text { Graham et al., } \\
\text { (158) }\end{array}$ & $\begin{array}{l}11 \text { individuals with ASD } \\
11 \text { age-matched controls }\end{array}$ & $\begin{array}{l}4-46 \\
4-33\end{array}$ & Brain & LC-LTQ Orbitrap MS & $\begin{array}{l}N \text {-carboxyethyl- } \gamma \text {-aminobutyric acid, } \\
\text { 5,6-dihydrouridine, 3-methoxytyramine }\end{array}$ & N/A \\
\hline $\begin{array}{l}\text { Kurochkin et al., } \\
\text { (159) }\end{array}$ & $\begin{array}{l}32 \text { individuals with } \mathrm{ASD} \\
40 \text { age-matched controls }\end{array}$ & $\begin{array}{l}2-60 \\
0-62\end{array}$ & Brain & UPLC-MS/MS & Glutathione disulfide, 5-oxoproline & Glutathione, $L-\gamma$-glutamyl-cysteine, L-cysteinyl-glycine, \\
\hline
\end{tabular}

Glutathione disulfide, 5-oxoproline

Glutathione, L- $\gamma$-glutamyl-cysteine, L-cysteinyl-glycine, 
a larger study performed on 48 children subjects and 53 agematched controls by Ming et al. (149). Using a combination of tandem ultrahigh-performance LC/tandem MS (UPLC/ MS/MS) and GC/MS, the group identified 82 metabolites that were significantly altered in patients with autism. These included decreased glycine, serine, threonine, alanine, $\beta$-alanine, histidine, and taurine, along with elevated transurocanate, glutaroylcarnitine, and 3-methylglutaroylcarnitine. Interestingly, both of the antioxidants, carnosine and uric acid, were also relatively decreased, while there were once again various metabolites associated with altered gut microbiota identified.

This was followed closely by a 2013 study led by Francois Emond et al. (151) describing increased concentrations of succinate and glycolate with decreased hippurate, phosphate, and several other small molecules. A third successive study from a group out of Italy (160) later also found statistically significant elevations glycolic acid, homovanillic acid, 3,4-dihydroxybutyric acid, and tryptophan. Elevations in glycolate have been associated with primary oxaluria type I; however, the phenomenon was also believed to be associated with yeast overgrowth. Both homovanillic acid and tryptophan, meanwhile, are metabolites of neurotransmitters suggesting once again the integral role of these molecules in psychiatric disorders. Finally, 3,4-dihydroxybutyric acid may be a normal component of human urine, although increased levels have been observed in cases of succinic semialdehyde dehydrogenase deficiency, a disorder in which patients may also present with autistic features (91).

Recently, in an attempt to fully explore the urine metabolome, Dieme et al. (152) detailed an even more expanded approach of combining urine ${ }^{1} \mathrm{H}$ NMR, ${ }^{1} \mathrm{H}{ }^{13} \mathrm{C}$ HSQC NMR, and LC-HRMS analyses. This kind of study presents a particularly significant statistical challenge given the differences in standardization and statistical analysis between each methodology. To address these challenges, the group performed multivariate analysis using two matched cohorts: a primary "training" subset for the initial identification of significant metabolites and a second "independent validation" subset. The two statistical models were then combined to yield a "data fusion block-scaling model" from which several dozen molecules of interest were determined. These included elevated levels of $\mathrm{N}$-acetylarginine, indoxyl and indoxyl sulfate with decreased levels of methylguanidine, and several other compounds that remained unidentified over the course of the study. A similar study was carried out by Bitar et al. (153) in a population of children with ASD from the Middle East. The group examined the urine of 40 children with ASD and 40 age-matched controls and utilized a similar "trainingvalidation" model. The group identified perturbations in several compounds previously outlined including tyrosine, 2 -hydroxybutyrate, creatine, and glutamate. Interestingly, this study also identified several newly recognized metabolites including trigonelline, cysteic acid, and guanine. Overall, these results once again pointed to abnormalities in amino acid and carbohydrate metabolism, as well as differences in oxidative stress pathways.

\section{Plasma Untargeted Metabolomic Studies}

Metabolomic studies on plasma have thus far tended to roughly corroborate the findings observed in urine, although specific differences have been proposed to be due to differences in renal clearance for some compounds. Kuwabara et al. (154), for instance, found that patients with autism had significantly elevated plasma levels of arginine and taurine with correspondingly low levels of 5 -oxoproline and lactic acid. The group utilized a technique known as capillary electrophoresis time-of-flight mass spectroscopy (CE-TOFMS), which relies on the use of an electric field to help separate components before they are subjected to MS. A total of 143 metabolites were identified, and the results of the study were confirmed by absolute metabolite quantification. The abnormalities found once again alluded to the role of oxidative stress and possible mitochondrial dysfunction in patients with ASD.

Significant changes in alternative metabolites were proposed by West et al. (155) a year later following two-tiered analysis of LC-MS/GC-MS data. The group used univariate, multivariate, and machine learning methods to identify significant elevations in aspartate, serine, DHEA-S, glutaric acid, and succinic acid. Decreases in the levels of citrate, creatinine, isoleucine, hydroxyphenyllactate, and glutamate were also found suggesting roles for altered branched-chain amino acid metabolism (isoleucine, hydroxyphenyllactate) and abnormal mitochondrial energy production (succinic acid, DHEA-S, citrate, aspartate, glutamate). Abnormal fatty acid metabolites were the main findings of another study utilizing ultraperformance LC quadrupole time-of-flight MS/MS (UPLC/Q-TOF MS/MS) (156). In this study of 173 total patients with autism, multiple logistic regression models identified 11 total metabolites that could be used to discriminate patients from matched controls. Samples were collected in the fasted state, and patients were instructed to follow a "standardized" diet and exercise regimen. Identified discriminative compounds included sphingosine 1-phosphate (S1P), decanoylcarnitine, pregnanetriol, docosahexaenoic acid (DHA), adrenic acid, and uric acid. The compounds S1P and DHA were felt to be most predictive of autism.

More recently, Rangel-Huerta et al. (157) published their findings on untargeted metabolomics of plasma samples from 30 children with ASD and 30 age-matched controls. The team subdivided ASD patients into groups consisting of those with some form of neurologic regression (AR) and those without (ANR). Utilizing HPLC-MS/MS, metabolic intermediates in the malate-aspartate shuttle, urea cycle, glucose-alanine cycle and beta-alanine, aspirate, and tryptophan breakdown pathways were found to differ significantly between controls and patients with ASD. Within the two subgroups, however, significant differences were found in the levels of the fatty acids decanoylcarnitine, arachidate, laurate, octanoylcarnitine, and myristate, as well as 7-methylurate and quinate.

\section{Brain Untargeted Metabolomics}

Metabolomic studies on brain tissue and CSF are somewhat lacking with, for instance, no studies thus far on CSF in patients with autism. The examination of postmortem brain samples, unlike studies on other tissues, however, brings with it unique 
challenges. The brains of patients with ASD have, for instance, been demonstrated to be slightly larger than age-matched controls (161). A few patient samples have also demonstrated thickening of the subependymal cell layer, heterotopias reflecting abnormal neuronal migration and multifocal cerebral and cerebellar dyplasias (162). Further, when conducting metabolomic studies, one has to also bear in mind the biochemical changes that occur in all human brains at the time of death. The human brain is made up of a relatively high proportion of lipids and proteins. The integrity of many of these compounds can be significantly compromised by normal biochemical processes at the time of death, including hypoxic-ischemic changes, inflammation, and apoptosis-necrosis $(163,164)$. Because of this, it can thus be difficult to determine which metabolomic perturbations are part of the "normal" process of death and which are inherent to ASD. That said, comparison to adequate age- and sex-matched control samples is critical for these analyses.

A study using LC-MS analyses for untargeted metabolomic analysis of brain tissue published by Graham et al. (158) on samples obtained from 11 deceased subjects with autism and 11 controls led to the identification of more than 20,000 "features" (i.e., raw metabolite ion fraction peaks), although further analytic refinements reduced this to 14,328 . The group prioritized the isolation of only the most statistically significant features, which resulted in a group of 37 compounds of interest, of which 18 molecules were increased in subjects and 19 decreased. These features were then matched to known spectral signatures so that the true chemical structure of analytes could be definitively identified. The group of statistically significant compounds included $N$-carboxyethyl- $\gamma$-aminobutyric acid, 5,6-dihydrouridine, and 3-methoxytyramine. However, when these features were used to build a predictive discriminatory model, none of the resultant statistically significant ion peaks could be definitively identified. While this is unfortunate, the authors did maintain that the study still highlighted the potential of this approach in ongoing biomarker research.

A second pioneering study conducted by Kurochkin et al. (159) examined postmortem prefrontal cortex samples of 32 individuals with ASD and 40 controls using LC-MS. Multidimensional scaling and normalization led to the identification of 1,366 unique analyte peaks with some statistical discrimination incidentally found based on the age of patients. Approximately $15 \%$ of the peaks demonstrated significant differences between ASD and control samples. The peaks corresponded with metabolites in several pathways including GSH metabolism, purine metabolism, pyruvate metabolism, propanoate metabolism, TCA cycle, galactose metabolism, starch and sucrose metabolism, nicotinate and nicotinamide metabolism, cysteine and methionine metabolism, and arginine and proline metabolism. The group further investigated how well these metabolite changes correlated with gene expression in different brain regions. Samples from both the frontal cortex and temporal cortex confirmed that genes linked to the altered metabolites were expressed at a higher rate than genes linked to metabolites showing no intensity difference in ASD. Human metabolomic data were also compared with data obtained by analysis of prefrontal cortex samples from two populations of nonhuman primates (chimpanzees and macaques). Once again, the metabolomic changes observed in humans with ASD proved to be unique to affected humans.

\section{THE FUTURE OF METABOLOMICS IN AUTISM}

Multiple lines of evidence have suggested over the years that children with ASDs are biochemically different than their peers. Yet it is only now, with the necessary advances in technology, that we have been able to narrow these down to the point where specific markers may one day be found. Indeed, the establishment of analyte databases like ChemSpider (165) and the Human Metabolome DataBase (166), along with integration tools like the Kyoto Encyclopedia of Genes and Genomes (167) and MetaboAnalyst (168), has enabled easier feature annotation and allowed for an expansion of the number of analytes that can be definitively identified.

As with any test or methodology, however, several key issues have been raised as potential impediments to its broader use. First, one has to bear in mind that untargeted metabolomic analyses, in their present form, are still relatively new and in some ways still require a particularly specialized set of skills to adequately interpret. If then used primarily as a screening tool, it would be difficult to educate and train community pediatricians, psychiatrists, and other care providers on the proper interpretation and use of such testing given the breadth of diagnostic abnormalities that can be ascertained. As well, one has to consider the implications of broader "screening" efforts. Certainly, untargeted metabolomics would be useful in ruling out IEMs, but whether or not this kind of testing would be most appropriate incorporated into newborn screening programs versus primarily used for confirmation of a clinical diagnosis remains to be seen $(169,170)$.

There are also many challenges encountered in the course of investigative experiments using this technology, at seemingly all stages. When planning these types of studies, for instance, one has to consider not only the choice of platform but also the number of both experimental and control samples to be assayed as these can significantly impact both feature identification and statistical analysis. The choice of sampling method also has significant implications as the number of metabolites will differ significantly. Investigators must ensure that all samples (subjects and controls) are collected and processed as uniformly as possible given that most platforms can quite easily reveal signs of improper handling (e.g., hemolysis, anticoagulation additives, improper solvent use, etc.), nutritional supplementation, environmental exposures, and fasting status. While we have detailed the various strengths and weaknesses of each analytical method, each requires careful calibration with appropriate standardization to ensure that results are of high quality. Despite these considerations, experimental errors may still be encountered. Batch effects, for example, may arise when a subset of samples exhibits abnormalities due to differences in retention times, reagents handling, and so on (171). Matrix effects and carryover are also phenomena commonly encountered in MS-based techniques and need to be addressed 
as well (172). Challenges remain even after analysis is carried out. While feature identification, for instance, has improved significantly, this area can be the most time-consuming aspect of studies (173), given the myriad of compounds found in the human body and the many ways in which these compounds may ionize. Multivariate analyses can be used to ascertain the statistically significant metabolite features, although even the use of these methods is still fraught with sources of error and bias (174).

Most studies have operated under the assumption that children with ASDs are largely biochemically homogenous; however, it is more likely that these individuals exhibit a myriad of biochemical phenotypes similar to the large heterogeneity observed clinically. While it would be ideal, for instance, to have a single or even a small number of "marker" molecules to help definitively distinguish these patients from controls, more than likely the answer may lie in identifying larger pathway perturbations or patterns. While some of the studies we have described here have pointed to broader metabolic disturbances like mitochondrial dysfunction or decreased energy metabolism, these results have not been replicable and have focused on only a small subset of compounds.

We have previously described our approach to untargeted metabolomics, which, in contrast to previous research models of pooled "cases" and "controls", instead takes an "n of 1" approach that we believe efficiently bridges both clinical and research spheres $(34,36,175,176)$. Here, a single patient's sample is analyzed by UPLC-MS/MS after which the raw spectral data from 700 to 1,000 unique compounds is compared to a "healthy reference population" to generate a comparative $z$ score. The use of this kind of control sample allows for the establishment of reference ranges for each compound and therefore facilitates the identification of any compounds or pathways outside the reference range in a single patient. From a clinical perspective, this allows for a comprehensive metabolic screen and identification of patient-specific global abnormalities. Meanwhile, from a research perspective, the approach allows for the gradual attainment and analysis of experimental samples, standardization in terms of compound identification, and quantification along with a reduced reliance on upfront statistical calculations.

\section{REFERENCES}

1. Association AP. Diagnostic and statistical manual of mental disorders (DSM$\left.5^{\circledR}\right)$. Arlington, VA American Psychiatric Pub (2013).

2. Kanner L. Autistic disturbances of affective contact. Nervous child (1943) 2(3):217-50.

3. Baio J, Wiggins L, Christensen DL, Maenner MJ, Daniels J, Warren Z, et al. Prevalence of autism spectrum disorder among children aged 8 years-autism and developmental disabilities monitoring network, 11 sites, United States, 2014. MMWR Surveill Summ (2018) 67(6):1. doi: 10.15585/mmwr.ss6706a1

4. Buescher AV, Cidav Z, Knapp M, Mandell DS. Costs of autism spectrum disorders in the United Kingdom and the United States. JAMA Pediatr (2014) 168(8):721-8. doi: 10.1001/jamapediatrics.2014.210

5. Lavelle TA, Weinstein MC, Newhouse JP, Munir K, Kuhlthau KA, Prosser LA. Economic burden of childhood autism spectrum disorders. Pediatrics (2014) 133(3):e520-529. doi: 10.1542/peds.2013-0763

6. Bouma R, Schweitzer R. The impact of chronic childhood illness on family stress: a comparison between autism and cystic fibrosis. J Clin Psychol
Untargeted metabolomics appears to be a promising research tool and has the potential to make significant discoveries about the underlying features of autism. While we believe our approach to be particularly well suited to this kind of work, there are of course many different ways in which this technology could be better adapted to ASD and improved. We have highlighted here the only metabolomic study of brain tissue in this population, and to the best of our knowledge, there have been no such studies conducted on CSF. Given the primarily neurologic manifestations of autism, this represents an important area of future research, particularly given the ease with which CSF may be obtained compared to postmortem brain tissue and the proven feasibility and reliability of its analysis (175). In addition, urine and plasma studies may be further optimized by more stringent characterization of patients' diets, supplement intake, and even microbiome. The minimization or even elimination of these kinds of variables can have a significant effect on the interpretation of metabolomic analyses. There is as well a great opportunity for combining both metabolomic and genomic data for an integrated and comprehensive approach to both diagnosis and ongoing management.

In the seven or so decades since Kanner's first descriptions of autism, we have made many strides in terms of diagnoses and treatment. Frustratingly, however, the answer to the question of "why" it occurs in the first place remains elusive. With the dawning of the so-called "omics" era, however, we have moved closer to just such an answer, and untargeted metabolomic studies may be one of the keys to finally making sense of this challenging disorder.

\section{AUTHOR CONTRIBUTIONS}

Both authors contributed equally to this work.

\section{ACKNOWLEDGMENTS}

We thank Dr. Adam Kennedy for assistance with figures.

(1990) 46(6):722-30. doi: 10.1002/1097-4679(199011)46:6<722::AID JCLP2270460605>3.0.CO;2-6

7. Allik H, Larsson JO, Smedje H. Health-related quality of life in parents of school-age children with Asperger syndrome or high-functioning autism. Health Qual Life Outcomes (2006) 4:1. doi: 10.1186/1477-7525-4-1

8. Benson PR. The impact of child and family stressors on the self-rated health of mothers of children with autism spectrum disorder: associations with depressed mood over a 12-year period. Autism (2018) 22(4):489-501. doi: $10.1177 / 1362361317697656$

9. De Rubeis S, Buxbaum JD. Genetics and genomics of autism spectrum disorder: embracing complexity. Hum Mol Genet (2015) 24(R1):R24-31. doi: $10.1093 / \mathrm{hmg} / \mathrm{ddv} 273$

10. Klei L, Sanders SJ, Murtha MT, Hus V, Lowe JK, Willsey AJ, et al. Common genetic variants, acting additively, are a major source of risk for autism. Mol Autism (2012) 3(1):9. doi: 10.1186/2040-2392-3-9

11. Chaste P, Roeder K, Devlin B. The yin and yang of autism genetics: how rare de novo and common variations affect liability. Annu Rev Genomics Hum Genet (2017) 18:167-87. doi: 10.1146/annurev-genom-083115-022647 
12. Schaefer GB, Mendelsohn NJ, Professional P, Guidelines C. Clinical genetics evaluation in identifying the etiology of autism spectrum disorders: 2013 guideline revisions. Genet Med (2013) 15(5):399-407. doi: 10.1038/gim.2013.32

13. Ghaziuddin M, Al-Owain M. Autism spectrum disorders and inborn errors of metabolism: an update. Pediatr Neurol (2013) 49(4):232-6. doi: 10.1016/j. pediatrneurol.2013.05.013

14. Geschwind DH, State MW. Gene hunting in autism spectrum disorder: on the path to precision medicine. Lancet Neurol (2015) 14(11):1109-20. doi: 10.1016/S1474-4422(15)00044-7

15. Asato MR, Goldstein AC, Schiff M. Autism and inborn errors of metabolism: how much is enough? Dev Med Child Neurol (2015) 57(9):788-9. doi: $10.1111 / \mathrm{dmcn} .12771$

16. Moeschler JB, Shevell M, Committee on G. Comprehensive evaluation of the child with intellectual disability or global developmental delays. Pediatrics (2014) 134(3):e903-918. doi: 10.1542/peds.2014-1839

17. Polyak A, Kubina RM, Girirajan S. Comorbidity of intellectual disability confounds ascertainment of autism: implications for genetic diagnosis. Am JMed Genet B Neuropsychiatr Genet (2015) 168(7):600-8. doi: 10.1002/ajmg.b.32338

18. Idle JR, Gonzalez FJ. Metabolomics. Cell Metab (2007) 6(5):348-51. doi: 10.1016/j.cmet.2007.10.005

19. Garrod AE. The incidence of alkaptonuria: a study in chemical individuality. Lancet (1902) 160(4137):1616-20. doi: 10.1016/S0140-6736(01)41972-6

20. Dalgliesh C, Horning E, Horning M, Knox KL, Yarger K. A gas-liquidchromatographic procedure for separating a wide range of metabolites occurring in urine or tissue extracts. Biochem J (1966) 101(3):792-810. doi: 10.1042/bj1010792

21. Gates SC, Sweeley CC. Quantitative metabolic profiling based on gas chromatography. Clin Chem (1978) 24(10):1663-73.

22. Horning E, Horning M. Human metabolic profiles obtained by GC and GC/ MS. J Chromatogr Sci (1971) 9(3):129-40. doi: 10.1093/chromsci/9.3.129

23. Devaux P, Horning M, Horning E. Benzyloxime derivatives of steroids. A new metabolic profile procedure for human urinary steroids human urinary steroids. Anal Lett (1971) 4(3):151-60. doi: 10.1080/00032717108059686

24. Alonso A, Marsal S, Julia A. Analytical methods in untargeted metabolomics: state of the art in 2015. Front Bioeng Biotechnol (2015) 3:23. doi: 10.3389/ fbioe. 2015.00023

25. Bothwell JH, Griffin JL. An introduction to biological nuclear magnetic resonance spectroscopy. Biol Rev Camb Philos Soc (2011) 86(2):493-510. doi: 10.1111/j.1469-185X.2010.00157.x

26. El-Aneed A, Cohen A, Banoub J. Mass spectrometry, review of the basics: electrospray, MALDI, and commonly used mass analyzers. Appl Spectrosc Rev (2009) 44(3):210-30. doi: 10.1080/05704920902717872

27. Koek MM, Jellema RH, van der Greef J, Tas AC, Hankemeier T. Quantitative metabolomics based on gas chromatography mass spectrometry: status and perspectives. Metabolomics (2011) 7(3):307-28. doi: 10.1007/s11306-010-0254-3

28. Theodoridis GA, Gika HG, Want EJ, Wilson ID. Liquid chromatographymass spectrometry based global metabolite profiling: a review. Anal Chim Acta (2012) 711:7-16. doi: 10.1016/j.aca.2011.09.042

29. Fuhrer T, Zamboni N. High-throughput discovery metabolomics. Curr Opin Biotechnol (2015) 31:73-8. doi: 10.1016/j.copbio.2014.08.006

30. Patti GJ, Yanes O, Siuzdak G. Innovation: metabolomics: the apogee of the omics trilogy. Nat Rev Mol Cell Biol (2012) 13(4):263-9. doi: 10.1038/nrm3314

31. Goodacre R, Vaidyanathan S, Dunn WB, Harrigan GG, Kell DB. Metabolomics by numbers: acquiring and understanding global metabolite data. Trends Biotechnol (2004) 22(5):245-52. doi: 10.1016/j.tibtech.2004.03.007

32. Schrimpe-Rutledge AC, Codreanu SG, Sherrod SD, McLean JA. Untargeted metabolomics strategies-challenges and emerging directions. J Am Soc Mass Spectrom (2016) 27(12):1897-905. doi: 10.1007/s13361-016-1469-y

33. Newgard CB. Metabolomics and metabolic diseases: where do we stand? Cell Metab (2017) 25(1):43-56. doi: 10.1016/j.cmet.2016.09.018

34. Miller MJ, Kennedy AD, Eckhart AD, Burrage LC, Wulff JE, Miller LA, et al. Untargeted metabolomic analysis for the clinical screening of inborn errors of metabolism. J Inherit Metab Dis (2015) 38(6):1029-39. doi: 10.1007/ s10545-015-9843-7

35. Argmann CA, Houten SM, Zhu J, Schadt EE. A next generation multiscale view of inborn errors of metabolism. Cell Metab (2016) 23(1):13-26. doi: 10.1016/j.cmet.2015.11.012
36. Kennedy AD, Miller MJ, Beebe K, Wulff JE, Evans AM, Miller LA, et al. Metabolomic profiling of human urine as a screen for multiple inborn errors of metabolism. Genet Test Mol Biomarkers (2016) 20(9):485-95. doi: 10.1089/gtmb.2015.0291

37. Newgard CB, An J, Bain JR, Muehlbauer MJ, Stevens RD, Lien LF, et al. A branched-chain amino acid-related metabolic signature that differentiates obese and lean humans and contributes to insulin resistance. Cell Metab (2009) 9(4):311-26. doi: 10.1016/j.cmet.2009.02.002

38. Wang TJ, Larson MG, Vasan RS, Cheng S, Rhee EP, McCabe E, et al. Metabolite profiles and the risk of developing diabetes. Nat Med (2011) 17(4):448-53. doi: $10.1038 / \mathrm{nm} .2307$

39. Bodi V, Sanchis J, Morales JM, Marrachelli VG, Nunez J, Forteza MJ, et al. Metabolomic profile of human myocardial ischemia by nuclear magnetic resonance spectroscopy of peripheral blood serum: a translational study based on transient coronary occlusion models. J Am Coll Cardiol (2012) 59(18):1629-41. doi: 10.1016/j.jacc.2011.09.083

40. Ussher JR, Elmariah S, Gerszten RE, Dyck JR. The emerging role of metabolomics in the diagnosis and prognosis of cardiovascular disease. J Am Coll Cardiol (2016) 68(25):2850-70. doi: 10.1016/j.jacc.2016.09.972

41. Kalhan SC, Guo L, Edmison J, Dasarathy S, McCullough AJ, Hanson RW, et al. Plasma metabolomic profile in nonalcoholic fatty liver disease. Metabolism (2011) 60(3):404-13. doi: 10.1016/j.metabol.2010.03.006

42. Roe B, Kensicki E, Mohney R, Hall WW. Metabolomic profile of hepatitis C virus-infected hepatocytes. PLoS One (2011) 6(8):e23641. doi: 10.1371/ journal.pone.0023641

43. Griffin JL, Shockcor JP. Metabolic profiles of cancer cells. Nat Rev Cancer (2004) 4(7):551-61. doi: 10.1038/nrc1390

44. Spratlin JL, Serkova NJ, Eckhardt SG. Clinical applications of metabolomics in oncology: a review. Clin Cancer Res (2009) 15(2):431-40. doi: 10.1158/10780432.CCR-08-1059

45. Applegarth DA, Toone JR. Incidence of inborn errors of metabolism in British Columbia, 1969-1996. Pediatrics (2000) 105(1):e10-0. doi: 10.1542/ peds.105.1.e10

46. Volkmar FR, Paul R, Klin A, Cohen DJ. Handbook of autism and pervasive developmental disorders, diagnosis, development, neurobiology, and behavior. Hoboken, NJ John Wiley \& Sons (2005). doi: 10.1002/9780470939352

47. Sanderson S, Green A, Preece MA, Burton H. The incidence of inherited metabolic disorders in the West Midlands, UK. Arch Dis Child (2006) 91(11):896-9. doi: 10.1136/adc.2005.091637

48. Pampols T. Inherited metabolic rare disease. In: de la Paz MP, Groft SC, editors. Rare disease epidemiology. (Dordrecht: Springer Netherlands) (2010). p. 397-431. doi: 10.1007/978-90-481-9485-8_23

49. Spilioti M, Evangeliou AE, Tramma D, Theodoridou Z, Metaxas S, Michailidi E, et al. Evidence for treatable inborn errors of metabolism in a cohort of 187 Greek patients with autism spectrum disorder (ASD). Front Hum Neurosci (2013) 7:858. doi: 10.3389/fnhum.2013.00858

50. Campistol J, Diez-Juan M, Callejon L, Fernandez-De Miguel A, Casado M, Garcia Cazorla A, et al. Inborn error metabolic screening in individuals with nonsyndromic autism spectrum disorders. Dev Med Child Neurol (2016) 58(8):842-7. doi: 10.1111/dmcn.13114

51. Brosco JP, Sanders LM, Dharia R, Guez G, Feudtner C. The lure of treatment: expanded newborn screening and the curious case of histidinemia. Pediatrics (2010) 125(3):417-9. doi: 10.1542/peds.2009-2060

52. Sikora DM, Pettit-Kekel K, Penfield J, Merkens LS, Steiner RD. The near universal presence of autism spectrum disorders in children with SmithLemli-Opitz syndrome. Am J Med Genet A (2006) 140(14):1511-8. doi: 10.1002/ajmg.a.31294

53. Witters P, Debbold E, Crivelly K, Vande Kerckhove K, Corthouts K, Debbold B, et al. Autism in patients with propionic acidemia. Mol Genet Metab (2016) 119(4):317-21. doi: 10.1016/j.ymgme.2016.10.009

54. Xiong X, Sheng X, Liu D, Zeng T, Peng Y, Wang Y. A GC/MS-based metabolomic approach for reliable diagnosis of phenylketonuria. Anal Bioanal Chem (2015) 407(29):8825-33. doi: 10.1007/s00216-015-9041-3

55. Blasco H, Veyrat-Durebex C, Bertrand M, Patin F, Labarthe F, Henique H, et al. A multiplatform metabolomics approach to characterize plasma levels of phenylalanine and tyrosine in phenylketonuria. JIMD Rep (2017) 32:6979. doi: 10.1007/8904_2016_568 
56. Thompson AJ, Tillotson S, Smith I, Kendall B, Moore SG, Brenton DP. Brain MRI changes in phenylketonuria. Associations with dietary status. Brain (1993) 116(Pt 4):811-21. doi: 10.1093/brain/116.4.811

57. de Groot MJ, Hoeksma M, Blau N, Reijngoud DJ, van Spronsen FJ. Pathogenesis of cognitive dysfunction in phenylketonuria: review of hypotheses. $\mathrm{Mol}$ Genet Metab (2010) 99 Suppl 1:S86-89. doi: 10.1016/j.ymgme.2009.10.016

58. Folling I. The discovery of phenylketonuria. Acta Paediatr Suppl (1994) 407:4-10. doi: 10.1111/j.1651-2227.1994.tb13440.x

59. Hertzberg VS, Hinton CF, Therrell BL, Shapira SK. Birth prevalence rates of newborn screening disorders in relation to screening practices in the United States. J Pediatr (2011) 159(4):555-60. doi: 10.1016/j.jpeds.2011.04.011

60. Reiss AL, Feinstein C, Rosenbaum KN. Autism and genetic disorders. Schizophr Bull (1986) 12(4):724-38. doi: 10.1093/schbul/12.4.724

61. Baieli S, Pavone L, Meli C, Fiumara A, Coleman M. Autism and phenylketonuria. J Autism Dev Disord (2003) 33(2):201-4. doi: 10.1023/A:1022999712639

62. Bilder DA, Kobori JA, Cohen-Pfeffer JL, Johnson EM, Jurecki ER, Grant ML. Neuropsychiatric comorbidities in adults with phenylketonuria: a retrospective cohort study. Mol Genet Metab (2017) 121(1):1-8. doi: 10.1016/j.ymgme.2017.03.002

63. Tint GS, Irons M, Elias ER, Batta AK, Frieden R, Chen TS, et al. Defective cholesterol biosynthesis associated with the Smith-Lemli-Opitz syndrome. N Engl J Med (1994) 330(2):107-13. doi: 10.1056/NEJM199401133300205

64. Nowaczyk MJ, McCaughey D, Whelan DT, Porter FD. Incidence of Smith-LemliOpitz syndrome in Ontario, Canada. Am J Med Genet (2001) 102(1):18-20. doi: 10.1002/1096-8628(20010722)102:1<18::AID-AJMG1376>3.0.CO;2-E

65. Nowaczyk MJ, Zeesman S, Waye JS, Douketis JD. Incidence of Smith-LemliOpitz syndrome in Canada: results of three-year population surveillance. J Pediatr (2004) 145(4):530-5. doi: 10.1016/j.jpeds.2004.06.045

66. Nowaczyk MJ, Waye JS, Douketis JD. DHCR7 mutation carrier rates and prevalence of the RSH/Smith-Lemli-Opitz syndrome: where are the patients? Am J Med Genet A (2006) 140(19):2057-62. doi: 10.1002/ajmg.a.31413

67. Waterham HR, Wanders RJ. Biochemical and genetic aspects of 7-dehydrocholesterol reductase and Smith-Lemli-Opitz syndrome. Biochim Biophys Acta (2000) 1529(1-3):340-56. doi: 10.1016/S1388-1981(00)00159-1

68. Jurevics H, Morell P. Cholesterol for synthesis of myelin is made locally, not imported into brain. J Neurochem (1995) 64(2):895-901. doi: 10.1046/j.1471-4159.1995.64020895.x

69. Mellon SH, Griffin LD. Neurosteroids: biochemistry and clinical significance. Trends Endocrinol Metab (2002) 13(1):35-43. doi: 10.1016/ S1043-2760(01)00503-3

70. Dietschy JM, Turley SD. Thematic review series: brain lipids. Cholesterol metabolism in the central nervous system during early development and in the mature animal. J Lipid Res (2004) 45(8):1375-97. doi: 10.1194/jlr.R400004-JLR200

71. Marcos J, Guo LW, Wilson WK, Porter FD, Shackleton C. The implications of 7-dehydrosterol-7-reductase deficiency (Smith-Lemli-Opitz syndrome) to neurosteroid production. Steroids (2004) 69(1):51-60. doi: 10.1016/j. steroids.2003.09.013

72. Tint GS, Seller M, Hughes-Benzie R, et al. Markedly increased tissue concentrations of 7-dehydrocholesterol combined with low levels of cholesterol are characteristic of the Smith-Lemli-Opitz syndrome. J Lipid Res (1995) 36(1):89-95.

73. Tierney E, Bukelis I, Thompson RE, Ahmed K, Aneja A, Kratz L, et al. Abnormalities of cholesterol metabolism in autism spectrum disorders. Am J Med Genet B Neuropsychiatr Genet (2006) 141B(6):666-8. doi: 10.1002/ ajmg.b.30368

74. Ferreira CR. Prevalence of adenylosuccinate lyase deficiency based on aggregated exome data. Mol Genet Metab Rep (2017) 10:81-2. doi: 10.1016/j.ymgmr.2016.12.009

75. Ciardo F, Salerno C, Curatolo P. Neurologic aspects of adenylosuccinate lyase deficiency. JChild Neurol (2001) 16(5):301-8. doi: 10.1177/088307380101600501

76. Jaeken J, Van den Berghe G. An infantile autistic syndrome characterised by the presence of succinylpurines in body fluids. Lancet (1984) 2(8411):1058-61. doi: 10.1016/S0140-6736(84)91505-8

77. Jurecka A, Zikanova M, Kmoch S, Tylki-Szymanska A. Adenylosuccinate lyase deficiency. J Inherit Metab Dis (2015) 38(2):231-42. doi: 10.1007/ s10545-014-9755-y

78. Donti TR, Cappuccio G, Hubert L, Neira J, Atwal PS, Miller MJ, et al. Diagnosis of adenylosuccinate lyase deficiency by metabolomic profiling in plasma reveals a phenotypic spectrum. Mol Genet Metab Rep (2016) 8:61-6. doi: 10.1016/j.ymgmr.2016.07.007

79. Stone T, Roberts L, Morris B, Jones P, Ogilvy H, Behan W, et al. Succinylpurines induce neuronal damage in the rat brain. In: Purine and Pyrimidine Metabolism in Man IX. New York, NY Springer (1998). p. 185-9. doi: 10.1007/978-1-4615-5381-6_36

80. Van den Berghe G, Bontemps F, Vincent MF, Van den Bergh F. The purine nucleotide cycle and its molecular defects. Prog Neurobiol (1992) 39(5):547-61. doi: 10.1016/0301-0082(92)90006-Z

81. Wyss M, Kaddurah-Daouk R. Creatine and creatinine metabolism. Physiol Rev (2000) 80(3):1107-213. doi: 10.1152/physrev.2000.80.3.1107

82. Braissant O, Bachmann C, Henry H. Expression and function of AGAT, GAMT and CT1 in the mammalian brain. In: Creatine and creatine kinase in health and disease. Dordrecht, The Netherlands Springer (2007). p. 67-81. doi: 10.1007/978-1-4020-6486-9_4

83. Schulze A. Creatine deficiency syndromes. In: Handbook of clinical neurology. Amsterdam, The Netherlands vol. 113. Elsevier (2013). p. 1837-43. doi: 10.1016/B978-0-444-59565-2.00053-8

84. Mercimek-Mahmutoglu S, Stoeckler-Ipsiroglu S, Adami A, Appleton R, Araujo HC, Duran M, et al. GAMT deficiency: features, treatment, and outcome in an inborn error of creatine synthesis. Neurology (2006) 67(3):480-4. doi: 10.1212/01.wnl.0000234852.43688.bf

85. van de Kamp JM, Betsalel OT, Mercimek-Mahmutoglu S, Abulhoul L, Grunewald S, Anselm I, et al. Phenotype and genotype in 101 males with X-linked creatine transporter deficiency. J Med Genet (2013) 50(7):463-72. doi: 10.1136/jmedgenet-2013-101658

86. Mercimek-Mahmutoglu S, Ndika J, Kanhai W, de Villemeur TB, Cheillan D, Christensen E, et al. Thirteen new patients with guanidinoacetate methyltransferase deficiency and functional characterization of nineteen novel missense variants in the GAMT gene. Hum Mutat (2014) 35(4):462-9. doi: 10.1002/humu.22511

87. Stockler-Ipsiroglu S, Apatean D, Battini R, DeBrosse S, Dessoffy K, Edvardson S, et al. Arginine:glycine amidinotransferase (AGAT) deficiency: clinical features and long term outcomes in 16 patients diagnosed worldwide. Mol Genet Metab (2015) 116(4):252-9. doi: 10.1016/j.ymgme.2015.10.003

88. Stockler S, Schutz PW, Salomons GS. Cerebral creatine deficiency syndromes: clinical aspects, treatment and pathophysiology. In: Creatine and creatine kinase in health and disease. Dordrecht, The Netherlands Springer (2007). p. 149-66. doi: 10.1007/978-1-4020-6486-9_8

89. Burrage LC, Thistlethwaite L, Stroup BM, et al. Untargeted metabolomic profiling reveals multiple pathway perturbations and new clinical biomarkers in urea cycle disorders. Genet Med (2019) doi: 10.1038/s41436-019-0442-0

90. Wolfenden C, Wittkowski A, Hare DJ. Symptoms of autism spectrum disorder (ASD) in individuals with mucopolysaccharide disease type III (Sanfilippo syndrome): a systematic review. J Autism Dev Disord (2017) 47(11):3620-33. doi: 10.1007/s10803-017-3262-6

91. Pearl PL, Gibson KM, Acosta MT, Vezina LG, Theodore WH, Rogawski MA, et al. Clinical spectrum of succinic semialdehyde dehydrogenase deficiency. Neurology (2003) 60(9):1413-7. doi: 10.1212/01.WNL.0000059549.70717.80

92. Novarino G, El-Fishawy P, Kayserili H, Meguid NA, Scott EM, Schroth J, et al. Mutations in BCKD-kinase lead to a potentially treatable form of autism with epilepsy. Science (2012) 338(6105):394-7. doi: 10.1126/science.1224631

93. Mulle JG, Sharp WG, Cubells JF. The gut microbiome: a new frontier in autism research. Curr Psychiatry Rep (2013) 15(2):337. doi: 10.1007/s11920-012-0337-0

94. Vuong HE, Hsiao EY. Emerging roles for the gut microbiome in autism spectrum disorder. Biol Psychiatry (2017) 81(5):411-23. doi: 10.1016/j. biopsych.2016.08.024

95. Khanna S, Tosh PK. A clinician's primer on the role of the microbiome in human health and disease. Mayo Clin Proc (2014) 89(1):107-14. doi: 10.1016/j.mayocp.2013.10.011

96. Young VB. The role of the microbiome in human health and disease: an introduction for clinicians. BMJ (2017) 356:j831. doi: 10.1136/bmj.j831

97. Mohajeri MH, Brummer RJM, Rastall RA, Weersma RK, Harmsen HJM, Faas $\mathrm{M}$, et al. The role of the microbiome for human health: from basic science to clinical applications. Eur J Nutr (2018) 57(Suppl 1):1-14. doi: 10.1007/s00394-018-1703-4

98. Hsiao EY, McBride SW, Hsien S, Sharon G, Hyde ER, McCue T, et al. Microbiota modulate behavioral and physiological abnormalities associated 
with neurodevelopmental disorders. Cell (2013) 155(7):1451-63. doi: 10.1016/j.cell.2013.11.024

99. Rosenfeld CS. Microbiome disturbances and autism spectrum disorders. Drug Metab Dispos (2015) 43(10):1557-71. doi: 10.1124/dmd.115.063826

100. Griffiths JA, Mazmanian SK. Emerging evidence linking the gut microbiome to neurologic disorders. Genome Med (2018) 10(1):98. doi: 10.1186/ s13073-018-0609-3

101. Tabouy L, Getselter D, Ziv O, Karpuj M, Tabouy T, Lukic I, et al. Dysbiosis of microbiome and probiotic treatment in a genetic model of autism spectrum disorders. Brain Behav Immun (2018) 73:310-9. doi: 10.1016/j. bbi.2018.05.015

102. Larsen PE, Dai Y. Metabolome of human gut microbiome is predictive of host dysbiosis. Gigascience (2015) 4:42. doi: 10.1186/s13742-015-0084-3

103. Kang DW, Ilhan ZE, Isern NG, Hoyt DW, Howsmon DP, Shaffer M, et al. Differences in fecal microbial metabolites and microbiota of children with autism spectrum disorders. Anaerobe (2018) 49:121-31. doi: 10.1016/j. anaerobe.2017.12.007

104. Wikoff WR, Anfora AT, Liu J, Schultz PG, Lesley SA, Peters EC, et al. Metabolomics analysis reveals large effects of gut microflora on mammalian blood metabolites. Proc Natl Acad Sci U S A (2009) 106(10):3698-703. doi: 10.1073/pnas.0812874106

105. Pedersen HK, Gudmundsdottir V, Nielsen HB, Hyotylainen T, Nielsen T, Jensen BA, et al. Human gut microbes impact host serum metabolome and insulin sensitivity. Nature (2016) 535(7612):376-81. doi: 10.1038/ nature 18646

106. De Angelis M, Piccolo M, Vannini L, Siragusa S, De Giacomo A, Serrazzanetti DI, et al. Fecal microbiota and metabolome of children with autism and pervasive developmental disorder not otherwise specified. PLoS One (2013) 8(10):e76993. doi: 10.1371/journal.pone.0076993

107. Sharon G, Cruz NJ, Kang DW, Gandal MJ, Wang B, Kim YM, et al. Human gut microbiota from autism spectrum disorder promote behavioral symptoms in mice. Cell (2019) 177(6):1600-18 e1617. doi: 10.1016/j.cell.2019.05.004

108. Coleman M, Blass JP. Autism and lactic acidosis. J Autism Dev Disord (1985) 15(1):1-8. doi: 10.1007/BF01837894

109. Lombard J. Autism: a mitochondrial disorder? Med Hypotheses (1998) 50(6):497-500. doi: 10.1016/S0306-9877(98)90270-5

110. Rossignol DA, Frye RE. Mitochondrial dysfunction in autism spectrum disorders: a systematic review and meta-analysis. Mol Psychiatry (2012) 17(3):290-314. doi: 10.1038/mp.2010.136

111. Hollis F, Kanellopoulos AK, Bagni C. Mitochondrial dysfunction in autism spectrum disorder: clinical features and perspectives. Curr Opin Neurobiol (2017) 45:178-87. doi: 10.1016/j.conb.2017.05.018

112. MacAskill AF, Atkin TA, Kittler JT. Mitochondrial trafficking and the provision of energy and calcium buffering at excitatory synapses. Eur $J$ Neurosci (2010) 32(2):231-40. doi: 10.1111/j.1460-9568.2010.07345.x

113. Sheng ZH, Cai Q. Mitochondrial transport in neurons: impact on synaptic homeostasis and neurodegeneration. Nat Rev Neurosci (2012) 13(2):77-93. doi: $10.1038 / \mathrm{nrn} 3156$

114. Oliveira G, Diogo L, Grazina M, Garcia P, Ataide A, Marques C, et al. Mitochondrial dysfunction in autism spectrum disorders: a populationbased study. Dev Med Child Neurol (2005) 47(3):185-9. doi: 10.1017/ S0012162205000332

115. Weissman JR, Kelley RI, Bauman ML, Cohen BH, Murray KF, Mitchell RL, et al. Mitochondrial disease in autism spectrum disorder patients: a cohort analysis. PLoS One (2008) 3(11):e3815. doi: 10.1371/journal.pone.0003815

116. Graf WD, Marin-Garcia J, Gao HG, Pizzo S, Naviaux RK, Markusic D, et al. Autism associated with the mitochondrial DNA G8363A transfer RNA(Lys) mutation. J Child Neurol (2000) 15(6):357-61. doi: $10.1177 / 088307380001500601$

117. Pons R, Andreu AL, Checcarelli N, Vila MR, Engelstad K, Sue CM, et al. Mitochondrial DNA abnormalities and autistic spectrum disorders. J Pediatr (2004) 144(1):81-5. doi: 10.1016/j.jpeds.2003.10.023

118. Giulivi C, Zhang YF, Omanska-Klusek A, Ross-Inta C, Wong S, HertzPicciotto I, et al. Mitochondrial dysfunction in autism. JAMA (2010) 304(21):2389-96. doi: 10.1001/jama.2010.1706

119. Gu F, Chauhan V, Kaur K, Brown WT, LaFauci G, Wegiel J, et al. Alterations in mitochondrial DNA copy number and the activities of electron transport chain complexes and pyruvate dehydrogenase in the frontal cortex from subjects with autism. Transl Psychiatry (2013) 3:e299. doi: 10.1038/tp.2013.68
120. Kent L, Gallagher L, Elliott HR, Mowbray C, Chinnery PF. An investigation of mitochondrial haplogroups in autism. Am J Med Genet B Neuropsychiatr Genet (2008) 147B(6):987-9. doi: 10.1002/ajmg.b.30687

121. Alvarez-Iglesias V, Mosquera-Miguel A, Cusco I, Carracedo A, PerezJurado LA, Salas A. Reassessing the role of mitochondrial DNA mutations in autism spectrum disorder. BMC Med Genet (2011) 12:50. doi: $10.1186 / 1471-2350-12-50$

122. Hadjixenofontos A, Schmidt MA, Whitehead PL, Konidari I, Hedges DJ, Wright $\mathrm{HH}$, et al. Evaluating mitochondrial DNA variation in autism spectrum disorders. Ann Hum Genet (2013) 77(1):9-21. doi: 10.1111/j.1469-1809.2012.00736.x

123. Chalkia D, Singh LN, Leipzig J, Lvova M, Derbeneva O, Lakatos A, et al. Association between mitochondrial DNA haplogroup variation and autism spectrum disorders. JAMA Psychiatry (2017) 74(11):1161-8. doi: 10.1001/ jamapsychiatry.2017.2604

124. Chauhan A, Gu F, Essa MM, Wegiel J, Kaur K, Brown WT, et al. Brain region-specific deficit in mitochondrial electron transport chain complexes in children with autism. J Neurochem (2011) 117(2):209-20. doi: 10.1111/j.1471-4159.2011.07189.x

125. Tang G, Gutierrez Rios P, Kuo SH, Akman HO, Rosoklija G, Tanji K, et al. Mitochondrial abnormalities in temporal lobe of autistic brain. Neurobiol Dis (2013) 54:349-61. doi: 10.1016/j.nbd.2013.01.006

126. Chauhan A, Chauhan V. Oxidative stress in autism. Pathophysiology (2006) 13(3):171-81. doi: 10.1016/j.pathophys.2006.05.007

127. Frustaci A, Neri M, Cesario A, Adams JB, Domenici E, Dalla Bernardina B, et al. Oxidative stress-related biomarkers in autism: systematic review and meta-analyses. Free Radic Biol Med (2012) 52(10):2128-41. doi: 10.1016/j. freeradbiomed.2012.03.011

128. Evans T, Siedlak S, Lu L, Fu X, Wang Z, McGinnis W, et al. The autistic phenotype exhibits a remarkably localized modification of brain protein by products of free radical-induced lipid oxidation. Am J Biochem Biotechnol (2008) 4(2):61-72. doi: 10.3844/ajbbsp.2008.61.72

129. Sajdel-Sulkowska EM, Xu M, Koibuchi N. Increase in cerebellar neurotrophin-3 and oxidative stress markers in autism. Cerebellum (2009) 8(3):366-72. doi: 10.1007/s12311-009-0105-9

130. Sajdel-Sulkowska EM, Xu M, McGinnis W, Koibuchi N. Brain region-specific changes in oxidative stress and neurotrophin levels in autism spectrum disorders (ASD). Cerebellum (2011) 10(1):43-8. doi: 10.1007/s12311-010-0223-4

131. Chauhan A, Audhya T, Chauhan V. Brain region-specific glutathione redox imbalance in autism. Neurochem Res (2012) 37(8):1681-9. doi: 10.1007/ s11064-012-0775-4

132. Endres D, Tebartz van Elst L, Meyer SA, Feige B, Nickel K, Bubl A, et al. Glutathione metabolism in the prefrontal brain of adults with highfunctioning autism spectrum disorder: an MRS study. Mol Autism (2017) 8:10. doi: 10.1186/s13229-017-0122-3

133. Sajdel-Sulkowska E, Lipinski B, Windom H, Audhya T, McGinnis W. Oxidative stress in autism: elevated cerebellar 3-nitrotyrosine levels. Am J Biochem Biotechnol (2008) 4(2):73-84. doi: 10.3844/ajbbsp.2008.73.84

134. Beaudet AL. Brain carnitine deficiency causes nonsyndromic autism with an extreme male bias: a hypothesis. Bioessays (2017) 39(8). doi: 10.1002/ bies. 201700012

135. Flanagan JL, Simmons PA, Vehige J, Willcox MD, Garrett Q. Role of carnitine in disease. Nutr Metab (Lond) (2010) 7:30. doi: 10.1186/1743-7075-7-30

136. Filipek PA, Juranek J, Nguyen MT, Cummings C, Gargus JJ. Relative carnitine deficiency in autism. J Autism Dev Disord (2004) 34(6):615-23. doi: 10.1007/ s10803-004-5283-1

137. Celestino-Soper PB, Violante S, Crawford EL, Luo R, Lionel AC, Delaby E, et al. A common X-linked inborn error of carnitine biosynthesis may be a risk factor for nondysmorphic autism. Proc Natl Acad Sci U S A (2012) 109(21):7974-81. doi: 10.1073/pnas.1120210109

138. Careaga M, Van de Water J, Ashwood P. Immune dysfunction in autism: a pathway to treatment. Neurotherapeutics (2010) 7(3):283-92. doi: 10.1016/j.nurt.2010.05.003

139. Onore C, Careaga M, Ashwood P. The role of immune dysfunction in the pathophysiology of autism. Brain Behav Immun (2012) 26(3):383-92. doi: 10.1016/j.bbi.2011.08.007

140. Meltzer A, Van de Water J. The role of the immune system in autism spectrum disorder. Neuropsychopharmacology (2017) 42(1):284-98. doi: 10.1038/ npp. 2016.158 
141. Hughes HK, Mills Ko E, Rose D, Ashwood P. Immune dysfunction and autoimmunity as pathological mechanisms in autism spectrum disorders. Front Cell Neurosci (2018) 12:405. doi: 10.3389/fncel.2018.00405

142. Atladottir HO, Pedersen MG, Thorsen P, Mortensen PB, Deleuran B, Eaton WW, et al. Association of family history of autoimmune diseases and autism spectrum disorders. Pediatrics (2009) 124(2):687-94. doi: 10.1542/peds.2008-2445

143. Careaga M, Rogers S, Hansen RL, Amaral DG, Van de Water J, Ashwood P. Immune endophenotypes in children with autism spectrum disorder. Biol Psychiatry (2017) 81(5):434-41. doi: 10.1016/j.biopsych.2015.08.036

144. Vargas DL, Nascimbene C, Krishnan C, Zimmerman AW, Pardo CA. Neuroglial activation and neuroinflammation in the brain of patients with autism. Ann Neurol (2005) 57(1):67-81. doi: 10.1002/ana.20315

145. Li X, Chauhan A, Sheikh AM, Patil S, Chauhan V, Li XM, et al. Elevated immune response in the brain of autistic patients. J Neuroimmunol (2009) 207(1-2):111-6. doi: 10.1016/j.jneuroim.2008.12.002

146. Morgan JT, Chana G, Pardo CA, Achim C, Semendeferi K, Buckwalter J, et al. Microglial activation and increased microglial density observed in the dorsolateral prefrontal cortex in autism. Biol Psychiatry (2010) 68(4):368-76. doi: 10.1016/j.biopsych.2010.05.024

147. Li S, Sullivan NL, Rouphael N, Yu T, Banton S, Maddur MS, et al. Metabolic phenotypes of response to vaccination in humans. Cell (2017) 169(5):862877 e817. doi: 10.1016/j.cell.2017.04.026

148. Yap IK, Angley M, Veselkov KA, Holmes E, Lindon JC, Nicholson JK. Urinary metabolic phenotyping differentiates children with autism from their unaffected siblings and age-matched controls. J Proteome Res (2010) 9(6):2996-3004. doi: 10.1021/pr901188e

149. Ming X, Stein TP, Barnes V, Rhodes N, Guo L. Metabolic perturbance in autism spectrum disorders: a metabolomics study. J Proteome Res (2012) 11(12):5856-62. doi: 10.1021/pr300910n

150. Mavel S, Nadal-Desbarats L, Blasco H, Bonnet-Brilhault F, Barthelemy C, Montigny F, et al. 1H-13C NMR-based urine metabolic profiling in autism spectrum disorders. Talanta (2013) 114:95-102. doi: 10.1016/j. talanta.2013.03.064

151. Emond P, Mavel S, Aidoud N, Nadal-Desbarats L, Montigny F, Bonnet-Brilhault F, et al. GC-MS-based urine metabolic profiling of autism spectrum disorders. Anal Bioanal Chem (2013) 405(15):5291-300. doi: 10.1007/s00216-013-6934-x

152. Dieme B, Mavel S, Blasco H, Tripi G, Bonnet-Brilhault F, Malvy J, et al. Metabolomics study of urine in autism spectrum disorders using a multiplatform analytical methodology. J Proteome Res (2015) 14(12):527382. doi: 10.1021/acs.jproteome.5b00699

153. Bitar T, Mavel S, Emond P, Nadal-Desbarats L, Lefevre A, Mattar H, et al. Identification of metabolic pathway disturbances using multimodal metabolomics in autistic disorders in a Middle Eastern population. J Pharm Biomed Anal (2018) 152:57-65. doi: 10.1016/j.jpba.2018.01.007

154. Kuwabara H, Yamasue H, Koike S, Inoue H, Kawakubo Y, Kuroda M, et al. Altered metabolites in the plasma of autism spectrum disorder: a capillary electrophoresis time-of-flight mass spectroscopy study. PLoS One (2013) 8(9):e73814. doi: 10.1371/journal.pone.0073814

155. West PR, Amaral DG, Bais P, Smith AM, Egnash LA, Ross ME, et al. Metabolomics as a tool for discovery of biomarkers of autism spectrum disorder in the blood plasma of children. PLoS One (2014) 9(11):e112445. doi: 10.1371/journal.pone.0112445

156. Wang H, Liang S, Wang M, Gao J, Sun C, Wang J, et al. Potential serum biomarkers from a metabolomics study of autism. J Psychiatry Neurosci (2016) 41(1):27-37. doi: 10.1503/jpn.140009

157. Rangel-Huerta OD, Gomez-Fernandez A, de la Torre-Aguilar MJ, Gil A, Perez-Navero JL, Flores-Rojas K, et al. Metabolic profiling in children with autism spectrum disorder with and without mental regression: preliminary results from a cross-sectional case-control study. Metabolomics (2019) 15(7):99. doi: 10.1007/s11306-019-1562-x

158. Graham SF, Chevallier OP, Kumar P, Türkoğlu O, Bahado-Singh RO. High resolution metabolomic analysis of ASD human brain uncovers novel biomarkers of disease. Metabolomics (2016) 12(4). doi: 10.1007/ s11306-016-0986-9

159. Kurochkin I, Khrameeva E, Tkachev A, Stepanova V, Vanyushkina A, Stekolshchikova E, et al. Metabolome signature of autism in the human prefrontal cortex. Commun Biol (2019) 2:234. doi: 10.1038/ s42003-019-0485-4

160. Noto A, Fanos V, Barberini L, Grapov D, Fattuoni C, Zaffanello M, et al. The urinary metabolomics profile of an Italian autistic children population and their unaffected siblings. J Matern Fetal Neonatal Med (2014) 27 Suppl 2:46-52. doi: 10.3109/14767058.2014.954784

161. Casanova MF. The neuropathology of autism. Brain Pathol (2007) 17(4):42233. doi: 10.1111/j.1750-3639.2007.00100.x

162. Wegiel J, Kuchna I, Nowicki K, Imaki H, Wegiel J, Marchi E, et al. The neuropathology of autism: defects of neurogenesis and neuronal migration, and dysplastic changes. Acta Neuropathol (2010) 119(6):755-70. doi: 10.1007/s00401-010-0655-4

163. Urban M, Enot DP, Dallmann G, Korner L, Forcher V, Enoh P, et al. Complexity and pitfalls of mass spectrometry-based targeted metabolomics in brain research. Anal Biochem (2010) 406(2):124-31. doi: 10.1016/j.ab.2010.07.002

164. Gonzalez-Riano C, Garcia A, Barbas C. Metabolomics studies in brain tissue: a review. J Pharm Biomed Anal (2016) 130:141-68. doi: 10.1016/j.jpba.2016.07.008

165. Pence HE, Williams A. ChemSpider: an online chemical information resource. J Chem Educ (2010) 87 (11);1123-1124. doi: 10.1021/ed100697w

166. Wishart DS, Jewison T, Guo AC, et al. HMDB 3.0-the human metabolome database in 2013. Nucleic Acids Res (2013) 41(Database issue):D801-807. doi: $10.1093 /$ nar/gks1065

167. Kanehisa M, Goto S, Sato Y, Furumichi M, Tanabe M. KEGG for integration and interpretation of large-scale molecular data sets. Nucleic Acids Res (2012) 40(Database issue):D109-114. doi: 10.1093/nar/gkr988

168. Xia J, Sinelnikov IV, Han B, Wishart DS. MetaboAnalyst 3.0-making metabolomics more meaningful. Nucleic Acids Res (2015) 43(W1):W251257. doi: 10.1093/nar/gkv380

169. Pellicano E, Stears M. Bridging autism, science and society: moving toward an ethically informed approach to autism research. Autism Res (2011) 4(4):271-82. doi: 10.1002/aur.201

170. Walsh P, Elsabbagh M, Bolton P, Singh I. In search of biomarkers for autism: scientific, social and ethical challenges. Nat Rev Neurosci (2011) 12(10):603-12. doi: 10.1038/nrn3113

171. Goh WWB, Wang W, Wong L. Why batch effects matter in omics data, and how to avoid them. Trends Biotechnol (2017) 35(6):498-507. doi: 10.1016/j. tibtech.2017.02.012

172. Dudzik D, Barbas-Bernardos C, Garcia A, Barbas C. Quality assurance procedures for mass spectrometry untargeted metabolomics. a review. J Pharm Biomed Anal (2018) 147:149-73. doi: 10.1016/j.jpba.2017.07.044

173. Dunn WB, Erban A, Weber RJ, Creek DJ, Brown M, Breitling R, et al. Mass appeal: metabolite identification in mass spectrometry-focused untargeted metabolomics. Metabolomics (2013) 9(1):44-66. doi: 10.1007/ s11306-012-0434-4

174. Worley B, Powers R. Multivariate analysis in metabolomics. Curr Metabolomics (2013) 1(1):92-107. doi: 10.2174/2213235X11301010092

175. Kennedy AD, Pappan KL, Donti TR, Evans AM, Wulff JE, Miller LAD, et al. Elucidation of the complex metabolic profile of cerebrospinal fluid using an untargeted biochemical profiling assay. Mol Genet Metab (2017) 121(2):8390. doi: 10.1016/j.ymgme.2017.04.005

176. Kennedy AD, Wittmann BM, Evans AM, Miller LAD, Toal DR, Lonergan S, et al. Metabolomics in the clinic: a review of the shared and unique features of untargeted metabolomics for clinical research and clinical testing. J Mass Spectrom (2018) 53(11):1143-54. doi: 10.1002/jms.4292

Conflict of Interest Statement: KG and SE are employees of Baylor College of Medicine, which has a partnership with Baylor Genetics and derives revenue from genetic testing.

Copyright (c) 2019 Glinton and Elsea. This is an open-access article distributed under the terms of the Creative Commons Attribution License (CC BY). The use, distribution or reproduction in other forums is permitted, provided the original author(s) and the copyright owner(s) are credited and that the original publication in this journal is cited, in accordance with accepted academic practice. No use, distribution or reproduction is permitted which does not comply with these terms. 